Published as: Wiley Interdiscip Rev Dev Biol. 2014 January ; 3(1): 113-134.

\title{
The Developmental Control of Size in Insects
}

\author{
H. Frederik Nijhout, \\ Department of Biology, Duke University
}

Lynn M. Riddiford, Janelia Farm Research Campus, Howard Hughes Medical Institute

Christen Mirth, Instituto Gulbenkian de Ciencia

Alexander W. Shingleton, Department of Zoology, Michigan State University

Yuichiro Suzuki, and

Department of Biology, Wellesley College

Viviane Callier

School of Life Sciences, Arizona State University

H. Frederik Nijhout: hfn@duke.edu; Lynn M. Riddiford: riddifordI@janelia.hhmi.org; Christen Mirth: christen.mirth@gmail.com; AlexanderW. Shingleton: shingle9@msu.edu; Yuichiro Suzuki: ysuzuki@wellesley.edu; Viviane Callier: vcallier@gmail.com

\section{Abstract}

The mechanisms that control the sizes of a body and its many parts remain among the great puzzles in developmental biology. Why do animals grow to a species-specific body size, and how is the relative growth of their body parts controlled to so they grow to the right size, and in the correct proportion with body size, giving an animal its species-characteristic shape? Control of size must involve mechanisms that somehow assess some aspect of size and are upstream of mechanisms that regulate growth. These mechanisms are now beginning to be understood in the insects, in particular in Manduca sexta and Drosophila melanogaster. The control of size requires control of the rate of growth and control of the cessation of growth. Growth is controlled by genetic and environmental factors. Insulin and ecdysone, their receptors and intracellular signaling pathways are the principal genetic regulators of growth. The secretion of these growth hormones, in turn, is controlled by complex interactions of other endocrine and molecular mechanisms, by environmental factors such as nutrition and by the physiological mechanisms that sense body size. Although the general mechanisms of growth regulation appear to be widely shared, the mechanisms that regulate final size can be quite diverse. 


\section{A. Background}

Body size and the sizes and shapes of body parts are among the most distinguishing characteristics of a species. Yet, the mechanisms that control body size and the shapes and sizes of body parts remain among the great unsolved puzzles in developmental biology.

During development, different structures (tissues, organs appendages) grow at different rates and start and stop at different times, and cell death may also occur as in the formation of digits. These processes cause the changes in size and shape we see during ontogeny. Different species have characteristically different sizes and shapes, and it seems reasonable to conclude that these arise due primarily to differences in the growth of their various parts although cell death of specific parts may also be involved. Thus, the mechanisms by which size and shape come about, and how those differ between species, are of natural interest to the study of development and evolution.

It is obvious that size is the mathematical product of growth rate and duration of growth, so to understand the control of size one needs to understand the mechanisms that control, not just growth, but the rate of growth, and also the mechanisms that control the duration of growth. Most work on the control of growth has been done with permanent cell culture lines. Such lines typically consist of transformed or immortalized cells, that is, cells that behave like cancer cells whose growth is independent of growth factors. Studies with such cells have taught us much about the molecular mechanism of cell growth and cell division, but they can tell us little about how the rates of cell growth are controlled in normal cells in intact animals. In multicellular organisms, growth is not an autonomous property of cells. When cells or tissues are taken from an animal and put into a culture medium, growth stops. And that is independent of the nutrient quality of the culture medium. For normal cells to grow in culture, they also need growth factors or hormones. In insects, ecdysone and insulinlike molecules appear to act as the most general growth promoting signaling factors ${ }^{1-6}$. To understand how growth is regulated in vivo, we need to know how growth factors are controlled and how they are distributed in time and space: some circulate generally, like hormones, others act locally via paracrine and autocrine signaling, and not all tissues are controlled the same way. In addition, there can be temporal and spatial variation in receptor expression ${ }^{7,8}$, that can modulate when and how cells respond to a particular growth stimulator.

Whereas the rate of growth is determined by the level of signaling a cell receives, the duration of the growth period is determined by mechanisms that control the onset and/or termination of growth signals. Timing mechanisms in development have been surprisingly little studied, in spite of the fact that development times in most organisms are extremely constant and sufficiently reliable that standard time tables for development have been constructed for most model organisms.

The developmental mechanisms that control body size and the relative sizes of appendages, and those that control timing events in development have been best studied in insects, particularly in two species, the tobacco hornworm Manduca sexta and the fruit fly Drosophila melanogaster. In this review we outline the studies that have elucidated these 
mechanisms, show how these are integrated into the developmental biology of the organism, and discuss open questions and avenue for future research.

\section{B. Control of Body Size}

\section{B.1. Background}

Because of their chitinous exoskeleton, insects can grow only by periodic shedding of this exoskeleton or cuticle in a process called molting. The apparent growth between molts seen in soft-bodied larval insects such as caterpillars or beetle grubs is due to the unfolding of the proteinaceous epicuticle that had been deposited in folds during the molt as the larva feeds and grows ${ }^{9}$. During this intermolt growth, the epidermis is continually depositing endocuticle (chitin plus protein) to strengthen the exoskeleton that is necessary for muscular locomotion. Normally the epidermis is polymorphic in that it sequentially makes the cuticle of the larva, pupa, and adult with most cells reprogramming their gene expression profiles, some cells dying at metamorphosis, and others arising anew. In the holometabolous insects with complete metamorphosis such as beetles, butterflies, bees and flies, there are nests of imaginal cells and imaginal discs for particular organs such as adult eyes and antennae that only proliferate during larval life, then differentiate at metamorphosis ${ }^{10}$.

Growth in insects as in the higher vertebrates (birds and mammals) only occurs in the immature stages, so adult body size is determined by the size the larva has reached when it stops feeding and begins metamorphosis. As a result, the control of adult body size is intimately connected to the mechanism that controls metamorphosis. Parts of this mechanism are now well understood and involve the interplay between two hormones, the sesquiterpenoid juvenile hormone ( $\mathrm{JH})$ and the steroid molting hormone, ecdysone $\mathrm{e}^{\dagger 11-18}$. Ecdysone is secreted periodically and induces molting, a process whereby the epidermis produces a new cuticle, then digests all of the old cuticle except for the exocuticle and epicuticle that are shed at the time of ecdysis. Juvenile hormone titers are high during larval development, and molts that occur in the presence of JH move a larva to successively larger larval instars.

The last larval instar is marked by a decline in JH titers; and in the absence of JH, ecdysone now has quite a different effect. The first low pulse of ecdysone that occurs in the absence of $\mathrm{JH}$ causes a larva to stop feeding and enter what is called the wandering stage, during which it seeks a suitable place to pupate ${ }^{16,19-22}$. This pulse also causes the polymorphic epidermis to switch its genetic program so that it can no longer produce a nymphal or larval cuticle but only an adult (hemimetabolous insects) or a pupal (holometabolous) cuticle when next exposed to a molting surge of ecdysteroid ${ }^{23-26}$. In response to this hormonal milieu, the internal tissues such as the nervous system either die, remodel or begin proliferation followed by differentiation as metamorphosis begins ${ }^{27}$. A second larger pulse of ecdysone then induces the molt to the pupa, or, in the higher Diptera, formation of the puparium from the old larval cuticle inside of which the pupa forms. Thus, body size is controlled indirectly by $\mathrm{JH}$, because its disappearance marks the last larval instar during which growth will stop. It is controlled more directly by ecdysone, because its secretion actually stops growth permanently. 
At each larval molt, body size increases by about the same factor, which leads to an exponential size increase from instar to instar, and this means that most of the body mass accumulates during the last larval instar. Manduca, for instance, grows from about 1.2 grams to about 12 grams during its last larval instar, so growth during this instar accounts for about $90 \%$ of final body mass ${ }^{28}$. In Drosophila, the last instar larva grows from $0.5 \mathrm{mg}$ to about $1.8 \mathrm{mg}$, gaining about $70 \%$ of its final mass during that stage ${ }^{29}$ (note that both Manduca and Drosophila lose weight after they stop feeding due to loss of gut content and metabolic losses during metamorphosis). Because most of an animal's mass is gained during the last larval instar, studies on the control of body size have focused largely on the developmental and physiological events that take place during the last larval instar. Two main processes have been of interest: the control of growth by insulin and ecdysone signaling, and the causes and consequences of the pulse of ecdysone secretion that terminates the growth phase.

\section{B.2. Control of growth}

\section{B.2.1. Genetic and environmental control of growth and size-There is} considerable genetic variation in body size both within and between insect populations. Perhaps the best studied is the variation in body size that accompanies changes in latitude and altitude. In general, within an insect species, populations from higher altitudes or latitudes are larger than populations from lower altitudes or latitudes, even when both are reared in the same environment ${ }^{30-38}$. More recent studies have identified clines in the frequency of numerous allozymes, DNA polymorphisms and chromosome inversions that parallel the clines for body size $30,39-44$. However, the relationship between these genetic markers and the developmental mechanisms that regulate body size remains largely unknown (although see ${ }^{45,46}$ ).

In contrast, we are beginning to understand many of the pathways that contribute to regulating growth rates and body size in response to environmental cues. A number of conditions can alter growth rates including nutrition 47,48 , temperature $32,38,49-52$, infection ${ }^{53-55}$, wounding ${ }^{56-58}$, oxygen levels ${ }^{59}$, larval crowding ${ }^{60}$ and the gut flora 55,61 . Temperature has been recently shown to affect body size by altering critical weight in Drosophila $^{62}$, an important endocrinological event that regulates the length of the growth period (see Section B.3. for details). Nutrition regulates growth both directly via the cellular concentrations of macronutrients such as amino acids ${ }^{63-65}$ and indirectly via endocrine signaling. The metabolic pathways that culminate in growth are influenced by all these factors 66 .

\section{B.2.2. The nutrition-sensitive pathways: insulin and target of rapamycin-} Studies of how nutrition regulates body size in the fruit fly, Drosophila melanogaster, have uncovered two nutrition-sensitive pathways that regulate growth rates: the insulin and Target of Rapamycin (TOR) pathways ${ }^{67-74}$ (Fig. 1). The TOR and insulin pathways share a number of key regulators, such as the serine/threonine protein kinase Protein Kinase B/Akt and the transcription factor Forkhead Box $\mathrm{O}(\mathrm{FoxO})^{75}$. Therefore, they are often referred to as the insulin/TOR signaling cascade. 
The nutritional environment determines the amount of insulin-like peptide (ILPs) produced by median neurosecretory cells (m-NSC) in the neuroendocrine centers in the brain of many insects ${ }^{70,76}$. Although the number of different ILPs varies by species, these peptides generally act to positively regulate growth ${ }^{70,77}$. In well-fed larvae of Drosophila, the production of three ILPs, ILP2, ILP3 and ILP5, remains high and stimulates the insulin signaling pathway in the cells of the body ${ }^{70}$, thereby promoting cell growth and proliferation. In response to starvation, the level ILP3 and ILP5 transcription decreases while ILP2 is blocked at the level of secretion 63, 70,78.

In Drosophila ILPs promote growth by binding to the single Insulin Receptor (InR) ${ }^{69}$, and activating a phosphorylation cascade through InR and the insulin receptor substrate Chico 79 (Fig. 1). Activation of Chico and InR results in the phosphorylation of phosphatidylinositide 3-kinase (Pi3K or Dp110) ${ }^{80}$. Pi3K converts a membrane lipid, phosphatidylinositol 4,5bisphosphate (PiP2), to phosphatidylinositol 3,4,5-trisphosphate (PiP3) ${ }^{67}$. The antagonist to $\mathrm{Pi} 3 \mathrm{~K}$ is PTEN, which converts PiP3 to PiP2 under conditions of low insulin signaling ${ }^{81-83}$. Increased PiP3 causes the localization of Akt to the membrane where it acts on several downstream targets to affect growth ${ }^{84}$. One of the actions of Akt is to phosphorylate FoxO ${ }^{85,86}$, a negative regulator of growth, thereby excluding it from the nucleus.

It is unclear whether m-NSCs which produce ILPs directly sense larval metabolic status to control growth. In adults, the m-NSCs do not express a key component of the carbohydrate sensing pathway, sulphonylurea receptor, and rely on the corpora cardiaca to sense blood glucose and regulate ILP secretion ${ }^{87}$. Whether these cells sense amino acids is unknown. What is known is that the insect storage tissue, the fat body, detects the intracellular availability of amino acids via the TOR pathway 63,78 (Fig. 1). The fat body then secretes a yet unidentified factor (fat body derived signal or FDS) that can stimulate the m-NSC to release ILPs to promote systemic growth. Also, proliferation in the brain neuroblasts is reactivated at the end of the first larval instar by ILPs secreted by the glia in response to FDS ${ }^{88,89}$. The fat body also detects the presence of dietary sugars and fats and releases Unpaired 2 (Upd2), a protein similar to type I cytokines in mammals ${ }^{90}$. Upd2 acts via the Janus kinase (JAK)/Signal Transducer and Activator of Transcription (STAT) pathway to inactivate the GABAergic neurons that normally inhibit release of ILPs by the m-NSCs. Hence the ILPs are released and stimulate systemic growth and fat storage. In this role Upd2 is acting similarly to mammalian leptin, and indeed human leptin can substitute for $\mathrm{Upd} 2$ in this system ${ }^{90}$.

There are at least two circulating factors dependent on nutritional state which regulate ILP action in Drosophila, apparently by binding with specific ILPs. The first is Imp-L2 which resembles Insulin Growth Factor Binding Protein (IGFBP) 7 of mammals, which is a tumor suppressor ${ }^{91}$. Imp-L2 is secreted by the fat body under conditions of starvation and binds ILP-2 and effectively prevents its action. It is also expressed in the ILP cells and the corpora cardiaca so may interact with ILPs at their source. In prepupae it is induced by ecdysone during imaginal disc and histoblast morphogenesis ${ }^{92}$. The second is Secreted Decoy of Insulin Receptor (SDR) which is secreted by the CNS and midgut surface glia throughout larval life and is not affected by starvation ${ }^{93}$. SDR negatively regulates growth by binding ILP3. 
B.2.3 Roles of ecdysone and juvenile hormone in regulating growth-Other developmentally important hormones, like ecdysone and $\mathrm{JH}$, affect larval growth in concert with insulin/TOR signaling (Fig. 1). Both of these developmental hormones act intracellularly. Ecdysone acts via a heterodimeric nuclear receptor comprised of the ecdysone receptor (EcR) that binds usually the active form of ecdysteroid 20hydroxyecdysone (20E) synthesized from ecdysone in peripheral tissues and Ultraspiracle (USP) that is the usual partner necessary for binding to the DNA response elements in the promoters of ecdysone-regulated genes ${ }^{8,94}$. JH acts via a novel helix-loop-helix protein Methoprene-tolerant (Met) by binding to its Pas B domain together with the EcR coactivator Taiman [also called Steroid Receptor Coactivator (SRC)] ( ${ }^{95}$; see ${ }^{96}$ for review). In Drosophila there is a second receptor due to the duplication of the ancestral gene germ cells expressed ( gce $)^{97,98}$. Met and gce can heterodimerize, but only in the absence of $\mathrm{JH}^{99}$. Initially Met and gce were thought to act redundantly during development ${ }^{100,101}$, but recent studies show that this is not true in all tissues ${ }^{17}$.

Insulin/TOR signaling in the prothoracic gland, the tissue that produces ecdysone, positively regulates ecdysone synthesis 1, 29,102-104 (Figs. 1,2). Ecdysone, in turn, negatively regulates the growth rate of the larval body 1,105 . The effect is mediated by EcR in the fat body via repression of the cell growth regulator Myc: a reduction in EcR expression in the fat body accelerates growth while this effect is lost with a coincidental reduction in the expression of Myc ${ }^{105}$. Autonomous changes in TOR-signaling in the fat body regulate the release of dILPs from the IPCs in the brain $^{78}$ as discussed in Section B.2.2, and it seems likely that this same mechanism links ecdysone-signaling in the fat body with systemic changes in insulinsignaling ${ }^{105}$. Further, dDOR, whose expression in the fat body (and possibly elsewhere) is negatively regulated by insulin-signaling and so is up-regulated when ecdysone levels are high, is itself a co-activator of EcR ${ }^{106}$. The result is a feed-forward loop whereby ecdysone potentiates its own activity via insulin-signaling.

Furthermore, although ecdysone appears to negatively regulate the growth of some tissues, such as the Drosophila larval fat body ${ }^{1,105}$, it appears to enhance the growth of other tissues such as the wing imaginal discs in fruit flies and lepidopterans 4, 5, 107-109. Twentyhydroxyecdysone alone appears to be sufficient for inducing mitotic cell divisions in explants of Manduca epidermis in tissue culture ${ }^{110}$. Thus, ecdysone's roles in growth appear to be tissue-specific (see also sections C.2 and C.3.2 below).

Juvenile hormone also regulates growth in lepidopterans and fruit flies, but in opposing manners. In Manduca JH suppresses the growth of the imaginal tissues in starved caterpillars ${ }^{111}$. Conversely, in Drosophila removal of the CA, the JH-producing gland, slows growth and produces small pupae ${ }^{112}$. This effect requires insulin/TOR signaling. Removing the CA in FoxO mutant animals results in animals of normal size (CK Mirth, HY Tang, S Makhon-Moore, S Salhadar, LM Riddiford, AW Shingleton, submitted). This suggests that JH regulates insulin/TOR signaling to control growth rates.

B.2.4 Growth regulation by other environmental cues-We do not yet know if all environmental stimuli that modify body size do so through the insulin/TOR, ecdysone or JH signaling pathways. However, changes in growth due to wounding $54,57,108,113,114$ or the 
presence of endosymbionts $54,55,61$ in Drosophila both appear to act through these pathways.

Larvae with injured or abnormally growing imaginal discs have slow growth across the entire body $56-58,115$. This results partly from the production of ILP8 by the injured discs, which suppresses growth in the surrounding tissues and inhibit ecdysone synthesis 113,114 . Feeding ecdysone does not restore growth of the body as a whole, but does restore growth of the uninjured imaginal discs ${ }^{108}$. Whether ILP8 acts though the same signaling cascade as the other ILPs is yet unknown. The bacteria that reside in larval guts of Drosophila can buffer some of the lost growth due to poor nutrition. Two species of gut microbes, Acetobacter pomorum and Lactobacillus plantarum, have been shown to accomplish this by regulating insulin/TOR and ecdysone signaling in the larva $55,61$.

Other environmental factors such as temperature and oxygen level can have a profound effect on growth and body size. In all insects, body size is inversely proportional to rearing temperature: adults are smaller at higher temperatures, a phenomenon called the inverse temperature size rule ${ }^{116,117}$. The mechanism by which this occurs is known for Manduca and emerges from the inverse and non-linear relationship between the effects of temperature on the growth rate and on the duration of the terminal growth phase ${ }^{117}$. Oxygen level can also affect body size in Manduca, and appears to do so by affecting the critical weight (see section B.3.1 below) (Fig. 2). Larvae reared under reduced oxygen tension have a lower critical weight and metamorphose at a smaller body size than larvae reared at normal oxygen levels 118,119 . Oxygen limitation appears to provide a mechanism for sensing body size. This is because, within an instar, the tracheal system (a set of air-filled tubes that deliver oxygen directly to all cells in an insect's body) does not grow even while body mass increases exponentially. At some point the tracheal system becomes incapable of meeting the ever increasing demand for oxygen. In Manduca this point corresponds to the critical weight (see section B.3.1 below), when the endocrine processes that lead to the cessation of growth and metamorphosis are triggered ${ }^{118}$.

B.2.5 Growth in post-feeding stages-Even though most growth occurs during the feeding stages in insect larvae, some additional growth occurs after feeding has stopped. Indeed, in holometabolous insects, most of the growth of the imaginal discs occurs during the prepupal and pupal stages, after the larva has stopped feeding and growing. In Manduca, ecdysone coordinates the amount of growth of imaginal discs in relation to overall body size in the post-feeding stages ${ }^{109}$. In the silkworm Bombyx mori the pupal fat body produces an IGF-like peptide (BIGFLP) in response to ecdysone that triggers adult development ${ }^{120}$. In Drosophila the fat body secretes a new ILP ILP6 in direct response to the pupariation peak of ecdysone, which subsequently remains high during pupal-adult development ${ }^{121,122}$. Both BIGFLP and ILP6 secretion allow tissues that grow mostly in the non-feeding stages to scale correctly with the growth acquired in the feeding stages.

\section{B.3. Mechanisms upstream of ecdysone secretion}

Ecdysone synthesis and secretion by the prothoracic glands is primarily driven by a neuropeptide, prothoracicotropic hormone (PTTH), synthesized by two pairs of 
neurosecretory cells in the lateral protocerebrum in both Manduca ${ }^{123}$ and Drosophila 20 (see ${ }^{124}$ for review) (Fig. 2). PTTH acts via Torso, a receptor tyrosine kinase, to stimulate extracellular signal-regulated kinase (ERK) phosphorylation ${ }^{125}$, which in turn activates the prothoracic gland to secrete ecdysone.

\section{B.3.1 Physiological triggers of PTTH secretion-The triggers for PTTH secretion} are diverse. The first to be discovered is the one found in the blood-sucking bug, Rhodnius prolixus, in which abdominal stretch receptors activated by the blood meal were found to initiate molting ${ }^{126}$. In other hemipterans Oncopeltus and Dipetalogaster, swelling of the abdomen also stimulates stretch receptors to send signals to the brain that trigger the secretion of PTTH and subsequently ecdysone ${ }^{126-128}$.

In larvae of Manduca, the molt is triggered when larvae reach the "critical weight", operationally defined as the weight above which the larva will metamorphose on time when starved $21,28,118,129-131$. The critical weight is achieved in about the middle of the last larval instar, when the larva is about half its final mass (Fig. 3). At the critical weight a series of physiological and molecular events are set in motion that make the brain competent to secrete PTTH. Among these are the decline in JH and the upregulation of JH-esterase (JHE), the principal enzyme that catabolizes JH. In the last larval instar JH inhibits PTTH secretion (see below), and removal of JH and its molecular effects is required for the brain to become competent to secrete PTTH. If the photoperiodic gate for that secretion is open, the brain secretes PTTH immediately; otherwise it waits until the opening of the next photoperiodic gate ${ }^{132}$. This photoperiodic gating of PTTH secretion occurs at all molts 22,132 . In Drosophila the pigment dispersing factor (PDF)-containing neurons that are involved in circadian rhythms synapse onto the PTTH-containing neurons, and $p d f$ null mutants have increased PTTH transcript with an altered periodicity ${ }^{20}$. However, whether molting is gated in Drosophila by photoperiod is not as clear ${ }^{29}$. More study is needed in this area.

Once the larva enters the final instar, $\mathrm{JH}$ can prolong the duration of the feeding period by suppressing the secretion of PTTH 11,21, 133, 134 and by potentially rendering the prothoracic gland insensitive to PTTH ${ }^{135}$. The disappearance of JH allows PTTH release at the next available photoperiodic gate 22,132 and subsequently the release of ecdysone to cause the cessation of feeding and the onset of wandering 19,136 and the change of commitment of the epidermis ${ }^{23}$. Topical application of $\mathrm{JH}$ during this instar prolongs larval feeding, leading to an increase in size although larvae that experience prolonged exposure to JH never metamorphose normally 19,137, 138. Starvation of Manduca at the onset of the final instar caused the JH titer to increase and on refeeding after a prolonged starvation, some of the larvae underwent a supernumerary molt ${ }^{139}$. This regulatory role of JH occurs only in the last larval instar of Manduca; in earlier instars JH is elevated at the time of the molt and appears to play no role in the timing of ecdysone secretion and molting ${ }^{11,16}$.

In contrast to Manduca and most other insects, JH cannot cause extra larval instars in Drosophila melanogaster. Continuous feeding on $\mathrm{JH}$ mimics methoprene and pyriproxifen had no effect on the length of either the first or the second instar, but prolonged the final third instar ${ }^{13,140}$. Curiously these larvae did not become noticeably larger. At the higher 
doses, the larval mortality was higher, but those that pupariated developed with normal timing to the pharate adult that was a mosaic of adult head, thorax and genitalia with a pupal abdomen ${ }^{140,141}$. The reason for this apparent insensitivity of the final instar higher dipteran endocrine system to JH is still a mystery.

Another simple but quite different mechanism has been described in the dung beetle, Onthophagus taurus ${ }^{142}$. In this species, starving a last-instar larva induces the metamorphic molt in 48 hours, provided the larva has attained a minimum viable size. This response to starvation is referred to as a 'bail out' mechanism that induces a molt when an animal's environment deteriorates. This response is adaptive because when a resource is exhausted, metamorphosing to an adult, albeit one of suboptimal size, ensures at least some capacity for reproduction.

\section{B.3.2 Non-canonical regulators of ecdysone secretion}

"Leaky" prothoracic glands: Although the brain and PTTH play central roles in the critical weight mechanism for molting, the fact that insects can molt in the absence of their brain has been known since the early classical experiments of Fukuda ${ }^{143}$, and has been confirmed in many species. In both Lepidoptera (Calpodes ethlius, Precis coenia, and Manduca) and Diptera (Drosophila melanogaster), when the PTTH signal is eliminated, larvae still exhibit a rise in ecdysone titers that triggers a molt, although it is delayed ${ }^{20,144,145}$. The fact that neck-ligated larvae eventually begin metamorphosis or pupate indicates either that the prothoracic glands have a physiologically significant autonomous secretory activity that acts as a positive feedback, or that there is an ecdysone-stimulating factor that does not come from the brain. In Bombyx mori, ecdysone secretion by the prothoracic glands can also be stimulated by insulin ${ }^{146}$, so it is possible that extracephalic sources of insulin-like peptides could be responsible for the delayed ecdysone secretion observed in neck-ligated larvae.

Ecdysteroidogenesis in the prothoracic glands is also controlled by other neurosecretory factors as well as neurally as revealed by studies on the silkworm Bombyx mori ${ }^{147}$. These include two circulating neuropeptides that inhibit the prothoracic glands, prothoracicostatic peptide and Bommomyosuppressin, at certain times during the molt. Also, there is direct tropic innervation by FMRF-related peptide- and orcokinin-containing neurons that maintain low levels of ecdysteroids during the feeding stage.

\section{B.4. Mechanisms downstream of ecdysone}

As briefly described above (section B.2.3), when a-ecdysone is secreted by the prothoracic glands, growth stops and a molt occurs. a-Ecdysone is converted by the peripheral tissues to the active molting hormone 20-hydroxyecdysone (20E) which acts on the epidermis to cause apolysis from the overlying cuticle followed by the secretion of the new cuticle $16,148,149$. Both the rise and the decline of the ecdysteroid titer are critical to orchestrate and coordinate the development throughout the animal. The early molecular events occurring during this process were first elucidated by Ashburner and his colleagues studying the puffing patterns of the polytene chromosomes of the salivary glands of Drosophila melanogaster at the onset of metamorphosis ${ }^{150}$. They found that $20 \mathrm{E}$ induced two early puffs, E74B and E75EF, within 10-15 minutes of addition of the hormone in vitro, then a second series of puffs at 
about $3 \mathrm{hr}$. The second series did not appear in the presence of cycloheximide, a protein synthesis inhibitor. Ashburner then proposed that the 20E bound to its receptor (EcR) which subsequently bound directly to the DNA and induced the mRNAs that formed the two early puffs. These mRNAs were thought to be transcription factors that then activated the "late" genes that formed the later puffs. He also proposed that the early transcription factors would feed back and turn off the synthesis of EcR. Beginning in the 1990's, this theory was validated by the cloning and characterization of the developmental expression of all the genes encoded by the chromosome puffs induced by $20 \mathrm{E}^{8,94,151}$. We now know that $20 \mathrm{E}$ binds to EcR when it is heterodimerized with USP ${ }^{152,153}$ and triggers a cascade of transcription factors beginning with E74B and E75A which is subsequently orchestrated by the changing ecdysteroid titer so that the proper sequential pattern of cellular events occurs to produce the glue in the case of the salivary glands or the new cuticle by the epidermis ${ }^{8}$. The same cascade of transcription factors is seen during both the larval and pupal molts in Manduca ${ }^{154}$. An example of how this cascade works relative to the formation of the new cuticle can be seen in the study of the patterning of the MHR3 transcription factor and subsequent cuticle deposition within a larval abdominal segment during the larval molt of Manduca ${ }^{138,155}$.

In contrast to the molting action of high levels of $20 \mathrm{E}$, low levels of $20 \mathrm{E}$ can cause developmental changes, particularly in the final larval instar and during the onset of metamorphosis. In Drosophila low levels of 20E that appear after the larva attains its critical weight ${ }^{156}$ cause derepression of patterning genes in the imaginal discs caused by the presence of unliganded EcR/USP sitting on the ecdysone response element (EcRE) in the promoter of these genes ${ }^{107,157}$. This rise in ecdysteroid also leads to the appearance of Broad, an ecdysone-inducible transcription factor that is both necessary and sufficient to specify the pupal state ${ }^{141,158}$ (Fig. 1). In the polymorphic abdominal epidermis of Manduca, Broad appears in response to the prewandering small peak of ecdysteroid, but only in the absence of $\mathrm{JH}^{159}$. Its appearance is coincident with the onset of pupal commitment in a particular pattern within the abdominal segment ${ }^{138,160}$.

In Manduca this commitment peak of ecdysteroid is composed of equal amounts of aecdysone and 20E. Yet in vitro experiments could not discern any effect of a-ecdysone, either alone or synergistically with $20 \mathrm{E}$, on eliciting the change in commitment ${ }^{23}$. aEcdysone by itself cannot cause a molt, but it can initiate mitoses in the pupal optic lobe and myogenic proliferation in the ventral diaphragm at the outset of adult development, both of which shut off as the $20 \mathrm{E}$ levels rise and differentiation is triggered ${ }^{161,162}$. In the ventral diaphragm, the addition of $\mathrm{JH}$ has no effect on proliferation but prevents the switch to differentiation. Also, in the prepupal epidermis, low levels of 20E stimulate mitosis, whereas high levels inhibit it ${ }^{110}$ (Fig. 1).

In Drosophila there are three isoforms of EcR, distinguished by different $\mathrm{N}$-terminal regions and generated by alternative splicing or by alternative promoters ${ }^{8,94}$. At the onset of metamorphosis EcR-A is high in the imaginal discs and the optic lobes as they proliferate in preparation for pupal differentiation whereas the B1 isoform is high in the larval tissues that are going to die and in larval abdominal neuroblasts that are proliferating ${ }^{163,164}$. Then during the pupal period the optic lobe acquires EcR-B1 which attains its peak expression 
during the first part of adult development when the optic lobe begins to differentiate in response to the adult peak of ecdysteroid ${ }^{162,164}$. JH given at the time of pupariation prevented the later appearance of EcR-B1 and proper differentiation of the optic lobe ${ }^{112}$. In contrast, genetic allatectomy caused premature appearance of EcR-B1 at the time of pupariation and premature differentiation of the ingrowing photoreceptors ${ }^{112}$. The null mutant of the JH receptor $\mathrm{Met}^{27}{ }^{165}$ also shows the same premature expression of EcR-B1 and development of the optic lobe as the allatectomized animals but develops to the adult which is blind apparently due to the anomalous morphogenesis of the lobula in the optic lobe ${ }^{112}$. By contrast, the loss of the $2^{\text {nd }} \mathrm{JH}$ receptor gce has no adverse effects of optic lobe development showing that the two receptors are not acting redundantly in all developmental processes ${ }^{17}$.

\section{B.5. Regulation of $\mathrm{JH}$ titers}

Understanding the regulation of the $\mathrm{JH}$ titer is critical to our understanding of final body size. The JH titer in the hemolymph is product of its synthesis, degradation and binding to proteins that transport $\mathrm{JH}$ around the body and prevent its degradation. The mechanisms underlying these processes remain unclear but the known regulators of JH biosynthesis during the larval period are summarized below. For a detailed account of the major regulators of JH titers, see ${ }^{14,166,167 .}$

B. 5.1. JH biosynthesis-JH biosynthesis occurs only in the CA and involves a series of enzymatic reactions that convert acetyl-CoA into $\mathrm{JH}^{14}{ }^{167,168}$. In several steps, acetyl-CoA is converted to isoprenoids, which condense to form farnesyl pyrophosphate that then is converted to farnesoic acid. In hemimetabolous insects methyl farnesoate is formed with subsequent epoxidation to give JH III that is secreted. In holometabolous insects, farnesoic acid is converted to $\mathrm{JH}$ acid, which is in turn converted to $\mathrm{JH}$ by $\mathrm{JH}$ acid $\mathrm{O}-$ methyltransferase (JHAMT). In Drosophila however methyl farnesoate (MF) is present in the $3^{\text {rd }}$ instar hemolymph as well as JH III and JH III bisepoxide ${ }^{169}$. MF binds to USP with high affinity and this interaction appears to be necessary for proper pupariation and metamorphosis 169,170 . The importance of JH biosynthesis in regulating the JH titers can be seen by the fact that when jhamt 3 is silenced in Tribolium, larvae undergo precocious metamorphosis and form miniature adults ${ }^{171}$. Expression of this enzyme tracks the JH titers closely and may therefore act as the rate-limiting step for JH biosynthesis ${ }^{171,172 .}$

Regulation of JH biosynthesis is both neuroendocrine and neuronal. The roles of allatotropins (stimulatory) and allatostatins (inhibitory) produced in brain neurosecretory cells have been elucidated in adults, but their roles during the larval stage remain largely unknown ${ }^{166,167}$. The adult Manduca allatotropin has no effect on the larval CA ${ }^{173}$, but in Bombyx the same peptide has been found to stimulate expression of short neuropeptide $\mathrm{F}$ (sNPF) in the corpora cardiaca (CC) ${ }^{174}$. However, sNPF suppresses JH production in the late penultimate and early final instar CA ${ }^{167}$. Drosophila has no gene that corresponds to the Manduca allatotropin ${ }^{175}$. In both the cockroach, Diploptera punctata, and Drosophila, glutamatergic neurons acting via NMDA signaling appear to stimulate JH biosynthesis by indirectly influencing jhamt expression ${ }^{176,177}$. In Drosophila, the binding of the NMDA receptor leads to the activation of Decapentaplegic (Dpp) signaling in the $\mathrm{CA}^{177}$. As a 
consequence, a target of Dpp signaling, Mothers against Dpp (MAD), activates the expression of jhamt. Finally, there is evidence that dopamine might also regulate $\mathrm{JH}$ biosynthesis in the CA of Manduca ${ }^{178}$. By binding to different receptors, dopamine can either have a stimulatory or an inhibitory effect on JH biosynthesis.

B.5.2. JH degradation- JH catabolism is regulated by two enzymes, JH esterase (JHE) and JH epoxide hydrolase (JHEH) ${ }^{179-181}$. JHE is made by the fat body and secreted into the hemolymph and can scavenge JH even when it is bound to the JH binding protein (JHBP), whereas JHEH acts in a tissue-specific manner ${ }^{181}$. While JHE has been more extensively studied, its role during the final instar remains somewhat unclear. As described above (section B.3.1), in Manduca JHE activity increases dramatically in both the hemolymph ${ }^{182,183}$ and in the tissues ${ }^{184}$ after the critical weight and the JH titer falls to undetectable allowing PTTH and ecdysone release to initiate metamorphosis. Inhibition of JHE in the cabbage looper, Trichoplusia ni, can result in the formation of larger larvae as a consequence of delayed JH degradation ${ }^{182}, 185$. In contrast, the expression profiles of many of the JHEHs track the JH titer in a manner that would be consistent if they were to act as key JH degrading enzymes ${ }^{186}$. Whether or not JHEH plays a key role in clearing the JH from the hemolymph remains to be seen.

B.5.3. JH binding proteins- $\mathrm{JH}$ must be carried to the rest of the body by proteins that tightly bind JH and protect it from degradation. In Manduca larvae a $29 \mathrm{kD}$ protein called the $\mathrm{JH}$ binding protein (JHBP) is made by the fat body and secreted into the hemolymph where it binds almost all of the $\mathrm{JH}$ secreted by the CA $14,166,187$. This protein protects $\mathrm{JH}$ from the common esterases in the hemolymph but not from the JHE. A second group of large, hemolymph proteins, lipophorins and hexamerins, may also help sequester JH. While many studies have elucidated the roles of lipophorins in adults, their role in regulating JH titers during the larval period remains poorly understood. The complex interplay of $\mathrm{JH}$ biosynthesis, degradation and binding to JH binding proteins is likely to explain the overall fluctuation of JH. If we are to understand how body size is regulated, further understanding of these processes will be essential.

\section{B.6. Mechanisms downstream of $\mathrm{JH}$ action}

The characterization of the $\mathrm{JH}$ receptor involved in growth and larval molting as Met only became clear in 2007 when Konopova and Jindra ${ }^{188}$ found that Met RNAi given to the early instar larva of the flour moth Tribolium castaneum caused precocious metamorphosis. Minakuchi et al. ${ }^{189}$ then showed an identical phenotype in Tribolium after injection of Krüppel homolog 1 (Kr-h1) RNAi. They also found that Kr-h1 was up-regulated by an exogenous $\mathrm{JH}$ mimic and was downstream of JH-Met signaling and upstream of the ecdysone-induced up-regulation of Broad at metamorphosis. In Drosophila loss of Krh1leads to the precocious appearance of Broad during the molt to the final instar ${ }^{177}$. As discussed above (section B.4), Broad is an ecdysone-induced transcription factor that is necessary for pupal commitment and pupal cuticle production in both Drosophila and Manduca ${ }^{141,160}$. No study has been done on Kr-h1 expression in Manduca. In Bombyx $\mathrm{Kr}-$ h1 mRNA is present in early instar larval epidermis and declines to trace levels in the final instar or in allatectomized larvae where it can be restored by application of $\mathrm{JH}^{190}$. 
Furthermore, studies in cell lines suggest that expression of $\mathrm{Kr}-\mathrm{h} 1$ is directly regulated by the JH-Met 2-Steroid receptor coactivator (SRC) complex ${ }^{190}$. Together all these studies have suggested a model for $\mathrm{JH}$ action in regulation of larval molting and metamorphosis whereby the presence of JH-Met-SRC complex in the larva prevents the up-regulation of Broad by ecdysone during the larval molt and during small peaks of ecdysone in the early final instar larva ${ }^{17}$ (Fig. 4).

\section{Control of Relative Sizes of Body Parts}

\section{C.1. Background}

All species of insects have the same general anatomy (head, thorax abdomen, 4 wings 6 legs, etc.), and species differ from each other by the relative sizes and shapes of these body parts. Although these structures can differ dramatically between species (think of the diversity of mouthparts, or the diversity of wing shapes), within a species their size and shape varies little (although there are interesting exceptions, as in the case of beetle horns and other sexually-selected traits ${ }^{191}$ ) and must thus be under considerable developmental control. But although body size is often thought of as being determined genetically ${ }^{192}$, it is actually subject to a considerable amount of plastic variation due to variation in nutrition, temperature and other environmental factors. If a species' body size varies, either due to genetic or environmental variation, the sizes of the appendages covary with body size so that their relative sizes remain fairly constant. Although it seems logical that such covariation should occur (smaller bodies have smaller wings and smaller legs), the mechanism that ensures proportional size of body parts at all body sizes is far from obvious. Parts that grow simultaneously at different but constant rates will naturally maintain a constant proportion to each other, but most body parts grow at varying rates (with exponential or, more commonly, sigmoidal kinetics) and for different periods of time, yet somehow match their final size to that of the body.

In hemimetabolous insects many body parts grow at the same time as the body and increase in the same proportion at each larval molt, but some, such as the wings and genitalia, increase disproportionally during the metamorphic molt when a larva becomes an adult. In holometabolous insects appendages develop as imaginal disc, and these do most of their growth after the larva has stopped feeding and growing. When a larva is undernourished and stops feeding to begin metamorphosis at a smaller than normal body size, the wing discs somehow have to alter their subsequent growth so their final size matches that smaller body size.

Growth is controlled at two levels. It is controlled centrally via the production of growth hormones and growth factors, and it is controlled locally at the cell level by regulating the response to growth factors, and in some cases by autocrine production of growth factors. The fact that body size varies with environmental factors and tissue and appendages adjust their size to body, suggests that size regulation of body parts cannot be an intrinsic property of cells. Size regulation of body parts, like that of the body as a whole, must be a systemic property that involves a mechanism that can assess size and a mechanism that controls the size at which growth stops. 
Although the covariation and scaling of appendages with body size is good, it is seldom perfect and this deviation is captured by the concept of allometry. Some body parts grow hypoallometrically (becoming relatively smaller with increasing body size) and others hyperallometrically. Some body parts of social insects, and many sexually selected traits such as beetle horns, have complex sigmoidal allometries and grow disproportionally large with increasing body size ${ }^{191,193-196}$. Each body part has a characteristic species-specific allometry, which suggests an underlying mechanism that systematically matches its growth pattern to overall size.

\section{C.2. Insulin \& ecdysone control of imaginal disc growth}

Just as insulin and ecdysone control the rate and duration of body growth in Drosophila larvae and likely the larvae of all holometabolous insects, so too do they influence the rate and duration of imaginal disc growth. Indeed, it is systemic changes in the titers of these hormones that are central to coordinating growth among discs and between the discs and the body as a whole, thereby resulting in a correctly proportioned adult.

Insulin signaling regulates the rate of imaginal disc growth. Perturbing insulin-signaling in individual imaginal discs, either by generating clones mutant for Inr, Chico, Pi3K or Akt, or by targeted expression of transgenes or dsRNAi, affects the final size of the disc without affecting the size of any other structure $68,79,82,84,197,198$. Consequently, the response of individual discs to circulating ILPs is regulated organ autonomously. The effect of insulinsignaling on final size is primarily mediated through a reduction in the rate of cell growth and proliferation ${ }^{198}$, with a consequential reduction in cell size and cell number in the final adult organs $79,86,199$.

Ecdysone regulates the timing of imaginal disc differentiation and morphogenesis. The changes in the ecdysone titer that follow attainment of critical size orchestrate the expression of genes involved in pattern specification and differentiation. For example, the movement of the morphogenetic furrow across the eye-antennal imaginal discs is regulated by ecdysone ${ }^{200,201}$, as is the induction of Distalless expression within bract cells of the pupal leg by EGFR signaling ${ }^{202}$. Activation of the ecdysone signaling pathway in imaginal discs organ-autonomously results in the premature expression of patterning genes $107,203$. Consequently, accelerating the timing of ecdysone synthesis not only reduces final body size $^{1}$, but also final organ size ${ }^{29}$, in large part because premature ecdysone secretion shortens the period of growth.

It is tempting to partition the roles that ecdysone- and insulin-signaling play in size control as regulation of the duration and rate of imaginal disc growth respectively. However, in order to generate a functioning adult organ, these two processes must be integrated at some level. Unsurprisingly, therefore, there is increasing evidence of considerable crosstalk between the insulin- and ecdysone-signaling pathways, both at a physiological and a molecular level. As discussed above, ecdysteroidogenesis is both regulated by and regulates insulin-signaling, with an increase in the ecdysone titer (through enhanced insulin-signaling in the PG) reducing systemic insulin-signaling via the fat body and slowing body growth ${ }^{1}$. Further, the release of ILP 8 from damaged imaginal discs appears to inhibit the release of 
ecdysteroid, possibly by antagonizing insulin-signaling in the PG, or by inhibiting the release of PTTH ${ }^{113,114}$.

These studies suggest that ecdysone is a negative growth regulator. However there is also considerable evidence that ecdysone is necessary to promote imaginal disc growth organautonomously 109, 200, 204-206. Indirect evidence suggests that this ecdysone-dependent imaginal disc growth is insulin-independent. Starvation or suppression of insulin-signaling reduces imaginal disc growth in larvae before attainment of critical size, when ecdysone levels are low, but not after critical size, when ecdysone levels are higher 205, 207. Additionally, activating ecdysone-signaling in the imaginal discs of starved larvae before attainment of critical size also appears to promote growth ${ }^{107}$.

Consequently, the role that ecdysone and insulin-signaling play in regulating imaginal disc growth is a complex one. Elevated ecdysone levels ostensibly reduce disc growth by suppressing systemic insulin-signaling. Yet at least some level of circulating ecdysone is necessary for imaginal disc growth and differentiation, potentially promoting growth in an insulin-independent manner. Why does ecdysone have these apparently contradictory roles in regulating imaginal-disc growth?

The answer may be that the imaginal discs in Drosophila have two types of growth: isomorphic growth that is nutrition- and insulin-dependent and morphogenetic growth that is ecdysone-dependent. Isomorphic growth ensures that size of the imaginal discs match the size of the body as a whole, which in turn reflects nutritional conditions. Morphogenetic growth accompanies differentiation of the imaginal discs into their final adult structure. Evidence for these two modes of growth come from Manduca ${ }^{111}$. In this species critical weight is marked by a decline in circulating JH, which de-represses the production of PTTH and ultimately stimulates the synthesis and release of ecdysone and metamorphosis ${ }^{21}$. Since imaginal disc development is completed in larvae that are no longer feeding, any growth associated with terminal morphogenesis must be independent of feeding ${ }^{205}$. It appears that Manduca use the absence of $\mathrm{JH}$ as a proximate cue to initiate morphogenetic growth ${ }^{111}$. Starving larvae at the outset of the final instar when JH levels are high stops this growth. In contrast, starving allatectomized larvae does not stop disc formation and growth. Normally in Manduca sucrose feeding at the onset of the final instar caused both the wing discs and the imaginal primordia to become pupally committed as signaled by the expression of Broad, a pupal-specifying transcription factor normally induced by ecdysone, whereas protein feeding was necessary for the subsequent morphogenetic growth 111, 208, 209. Importantly, insulin can substitute for this nutrient input in starved animals and cause the upregulation of Broad in the discs and primordia, apparently by a direct action on these tissues to prevent the suppressive action of $\mathrm{JH}^{209}$.

In Drosophila, where elimination of JH is not necessary for ecdysone synthesis and metamorphosis, we suggest that it is the increase in the ecdysone titer itself that is the proximate cue for morphogenetic growth. Under this hypothesis, during normal Drosophila development up to critical weight, insulin-signaling drives isomorphic growth of the discs. However, once a larva has attained critical weight, has stopped feeding and is preparing to pupariate, a rising ecdysteroid titer may also initiate morphogenetic growth, both by 
suppressing systemic insulin-signaling ${ }^{1}$ and allowing nutrition- and insulin-independent growth of the imaginal discs 57,107 . At the same time, ecdysone-dependent autophagy of the fat body will provide nutrients necessary for morphogenetic growth ${ }^{210}$. The observation that very high levels of ecdysone inhibit imaginal disc growth ${ }^{4,109}$ suggests that morphogenetic growth continues until ecdysteroid levels rise above a growth-inhibitory threshold later in development, determining the final size of the corresponding adult organ. It is important to note, however, that isomorphic growth continues even after the attainment of critical weight and the initiation of morphogenetic growth. Indeed, changes in nutrition only affect final body and organ size once critical weight is achieved, while changes in insulin-signaling continue to affect organ size up until the beginning of pupariation, well after a larvae has stopped feeding ${ }^{211}$. This later period of isomorphic growth appears to be at least partially regulated by the release of dILP6 by the fat body, in response to both starvation and circulating ecdysteroids ${ }^{212}$. One hypothesis is that dILP6 regulates the final growth of the discs so that they are appropriate to the size of the body as a whole, by reflecting the quantity of nutrients stored in the fat body.

\section{C.3. Control of relative growth}

Individuals of a species vary in size due to differences in their genetics, nutrition, temperature and other environmental factors, and simply because of random noise in the complex mechanisms that control size. Whatever the cause of the differences and variation in body size, the sizes of appendages and other body parts must co-vary. The simplest way in which this co-variation could occur is if there is no integrative control, but that all body parts simply grow at their own characteristic linear or exponential rates, and differences in size come about by differences in the duration of growth. If all body parts (and by implication, the body as a whole) stop growing at the same time then their final sizes will have a characteristic proportion to each other and the body as a whole. The only control would be the mechanism that stops growth. Such a simple mechanism is unlikely to occur in nature because different body parts start and stop their growth at different times in development. In hemimetabolous insects growth of appendages is episodic and occurs only at each molt. And in holometabolous insects most of the growth of appendages occurs during metamorphosis, after the body as a whole has stopped growing.

C.3.1. Hemimetabolous insects-Except for the wings and external genitalia, growth of appendages is gradual with body, although change in shape indicates growth is not isometric. Appendages generally grow incrementally at each molt. Cell division occurs only during a molt because cell division is stimulated by the secretion of ecdysone and occurs soon after apolysis (separation of the epidermis from the cuticle). If all epidermal cells divide and maintain their size and shape, then surface areas should double at each molt and linear measures (e.g. the length of a leg segment or the width of a head capsule) should increase $2^{0.5}=1.41$-fold at each molt (if it is volume that doubles, the linear increment would be $2^{0.33}=1.26$-fold). This incremental increase is called Dyar's Rule, which states that the growth increment (size of a structure divided by its size in the previous instar) is constant from instar to instar. A constant growth increment results in an exponential increase in size from instar to instar. Note that this is not the same as exponential growth since instar length is variable and growth is episodic, occurring only when a larva molts. In Manduca the 
head capsule width and body length both have a growth increment of about 1.75, and in Oncopeltus fasciatus, leg length has a growth increment of about $1.5^{213}$. The growth increment is seldom exactly 1.26 but varies from about 1.21 to 2.1 depending on the species and structure measured ${ }^{214,215}$. Deviation from the ideal increment could be due to the fact that not all epidermal cells divide, or that some cells divide more than once. The latter is likely to be the case in the excessive increase in size of wings during the metamorphic molt. Another possibility is that all cells divide but not all grow to the same size after metamorphosis, either because of a change in ploidy (which increases cell volume) or an change in shape (e.g. from columnar to squamous, or vice versa), which simply changes the surface area of the cell that deposits the cuticle. Which of these alternatives accounts for the changes in size and shape at each molt has not yet been investigated.

The primary focus of studies on relative size in Hemimetabola has been on the molecular mechanisms that underlie differences in relative sizes of appendages. The wings pads in Oncopeltus, like the legs, have a growth increment of about 1.5 during larval molts, but in the molt to the adult the increase is exceptionally large, with an increment of about $3^{213}$. The increased growth at metamorphosis is controlled by the disappearance of the transcription factor Broad $(\mathrm{Br})$ which in the hemimetabolous insects appears in the embryo and is present throughout nymphal life $213,216-218$. When $b r$ is expressed during the Oncopeltus nymphal molt, the larval size increment is maintained ${ }^{213}$. When $b r$ expression is knocked down by $b r$ RNAi in the early instars, isometric growth of the legs and antennae is unaffected but the anisometric growth of the wing pads is reduced. At the end of larval life, $b r$ expression ceases and the metamorphic molt with an excessive increase in wing disc size ensues. Treatment of a last-instar larva with JH maintains $b r$ expression and inhibits the excessive growth increment of the wing. By contrast, treatment with precocene, which destroys the $\mathrm{CA}^{219,220}$, causes premature metamorphosis and an increased growth increment of wing pad at the next molt. Similar findings were recently reported for the German cockroach Blattella germanica 218 .

In Oncopeltus, the tibia of the third thoracic leg is moderately larger than the others and in Acheta domesticus all leg segments (femur, tibia and tarsus) of the third abdominal legs are greatly enlarged to form the jumping legs. The Hox gene Ultrabithorax (Ubx) is expressed in the enlarged segments of the legs of these species, and its expression coincides with the time during which these segments become enlarged. Suppression of $U b x$ prevents embryonic enlargement of these leg segments 221,222 . Thus, it appears that Ubx sets up the initial differences in size of appendages and appendage segments, at least in the third thoracic segment. In Locusta migratoria the length of the femur scales geometrically with mass in successive larval instars ${ }^{223}$, indicating that the initial size advantage is simply maintained. However, the increase during the molt to the adult is disproportionally large ${ }^{223}$, much like that of the wings in Oncopeltus.

C.3.2. Holometabolous insects-In holometabolous insects the adult morphology does not develop gradually as it does in hemimetabolous insects, but the sizes and proportions of adult body parts emerge after larval life, during metamorphosis. Adult appendages develop from epidermal tissues that are either set aside during embryonic or larval development as imaginal discs, or from small regions of larval epidermis that remain undifferentiated until 
metamorphosis ${ }^{10}$. For instance, the horns of scarab beetles develop by proliferation of small regions of epidermis ${ }^{224,225}$, very much like the legs of adult Manduca that develop from small patches of epidermal cells of the larval legs 111, 226, 227.

Horn development and allometry in scarab beetles have been extensively studied and appears to be under multilevel control ${ }^{225}, 228-230$. In dung beetles horn development and horn size are conditional traits. Small and medium size males have small horns or no horns at all, and large males have disproportionally large horns ${ }^{231-235}$. The locations where the horns will grow are marked by the expression of Distal-less and Homothorax 224, 225 . Knock-down of Distal-less inhibits the growth of both head and thoracic horns in large males but not in small and medium males, whereas knockdown of Homothorax only inhibits the growth of thoracic horns but in all size classes.

In rhinoceros beetles, knock-down of the insulin receptor with dsRNA after larvae stopped feeding and entered metamorphosis caused a $2 \%$ reduction in wing size and a $16 \%$ reduction in horn size in the adult; genital appendage size was not affected ${ }^{230}$. Clearly tissues differ in their sensitivity to insulin signaling and the degree of insulin signaling can control the relative sizes of these body parts, as is also the case in Drosophila 198, 236.

Growth and allometry of wings in Manduca is also under multiple levels of control. In vitro tissue culture has shown that growth of wing discs requires both insulin and ecdysone signaling. Either factor alone stimulates only limited growth, but together they act synergistically to stimulate growth at the same rate observed in vivo ${ }^{4,5}$. Variation in either ecdysone or insulin could thus control the rate of wing growth. Insulin signaling is generally thought to be responsive to nutrition, but in Manduca growth of the wing disc becomes independent of nutrition about the middle of the last larval instar ${ }^{205}$, when the larva passes the critical weight and has achieved about half their final size. The wing (like all other imaginal appendages) grows during the prepupal and pupal stages, after the body has stopped growing.

Body size can vary plastically due to variation in nutrition, yet wings grow to exactly the right proportion to the body, indicating that they do not have a genetically determined size. In Manduca it appears that the body controls the growth of its wings via the secretion of ecdysone. Control occurs during the prepupal stage when both the level of ecdysone (which controls the rate of cell division), and the timing of ecdysone secretion (which controls the duration of cell division in the wing) determine the amount of growth of the wing ${ }^{109}$. Thus the growth and size of the wings is controlled by the central nervous system, via the secretion of the PTTH that stimulates ecdysone secretion. In effect, the CNS controls the correct scaling of body parts with variation in overall body size. The match is not entirely perfect. At very large body sizes, wings do not quite grow large enough because development time does not scale precisely with body size. Although at small body sizes the duration of ecdysone secretion is shorter during the prepupal stage, at large body sizes it is not significantly longer than at normal body sizes ${ }^{109,237}$. In Drosophila, by contrast, imaginal disc growth depends on insulin signaling and it is possible that circulating insulin levels depend on body size. Together with the organ-autonomous sensitivity to insulin signaling 198,236 , this could be the mechanism by which organs of different sizes scale with 
body size. The mechanisms by which body size controls the pattern and amount of circulating ecdysone and insulin is still not understood.

\section{References}

1. Colombani J, Bianchini L, Layalle S, Pondeville E, Dauphin-Villemant C, Antoniewski C, Carre C, Noselli S, Leopold P. Antagonistic actions of ecdysone and insulins determine final size in Drosophila. Science. 2005; 310:667-670. [PubMed: 16179433]

2. Hafen E. Interplay between growth factor and nutrient signaling: Lessons from Drosophila TOR. Current Topics in Microbiology and Immunology. 2003; 279:153-167. [PubMed: 14560957]

3. Oldham S, Stocker H, Laffargue M, Wittwer F, Wymann M, Hafen E. The Drosophila insulin/IGF receptor controls growth and size by modulating PtdInsP(3) levels. Development. 2002; 129:41034109. [PubMed: 12163412]

4. Nijhout HF, Grunert LW. Bombyxin is a growth factor for wing imaginal disks in Lepidoptera. Proceedings of the National Academy of Sciences. 2002; 99:15446-15450.

5. Nijhout HF, Smith WA, Schachar I, Subramanian S, Tobler A, Grunert LW. The control of growth and differentiation of the wing imaginal disks of Manduca sexta. Developmental Biology. 2007; 302:569-576. [PubMed: 17112498]

6. Wu Q, Brown M. Signaling and function of Insulin-like peptides in insects. Annual Review of Entomology. 2006; 51:1-24.

7. Mouillet J-F, Henrich VC, Lezzi M, Vögtli M. Differential control of gene activity by isoforms A, B1 and B2 of the Drosophila ecdysone receptor. European Journal of Biochemistry. 2001; 268:1811-1819. [PubMed: 11248701]

8. Riddiford LM, Cherbas P, Truman JW. Ecdysone receptors and their biological actions. Vitam Horm. 2001; 60:1-73. [PubMed: 11037621]

9. Wolfgang WJ, Riddiford LM. Cuticular morphogenesis during continuous growth of the final instar larva of a moth. Tissue \& Cell. 1981; 13:757-772. [PubMed: 7330856]

10. Švácha P. What are and what are not imaginal discs: Reevaluation of some basic concepts (Insecta, Holometabola). Developmental Biology. 1992; 154:101-117. [PubMed: 1426619]

11. Nijhout, HF. Insect Hormones. Princeton, NJ: Princeton University Press; 1994.

12. Riddiford LM. Hormone receptors and the regulation of insect metamorphosis. Receptor. 1993; 3:203-209. [PubMed: 8167571]

13. Riddiford LM, Hiruma K, Zhou X, Nelson CA. Insights into the molecular basis of the hormonal control of molting and metamorphosis from Manduca sexta and Drosophila melanogaster. Insect Biochemistry and Molecular Biology. 2003; 33:1327-1338. [PubMed: 14599504]

14. Goodman, WG.; Cusson, M. The juvenile hormones. In: Gilbert, LI., editor. Insect Endocrinology. London: Academic Press; 2012. p. 310-365.

15. Riddiford, LM. Hormones and Drosophila development. In: Bate, M.; Martinez-Arias, A., editors. The Development of Drosophila melanogaster. Vol. 2. Plainview: Cold Spring Harbor Press; 1993.

16. Riddiford LM. Cellular and molecular actions of juvenile hormone. I. General considerations and premetamorphic actions. Advances in Insect Physiology. 1994; 24:213-227.

17. Riddiford LM. How does juvenile hormone control insect metamorphosis and reproduction? General and Comparative Endocrinology. 2012; 179:477-484. [PubMed: 22728566]

18. Truman JW, Riddiford LM. The morphostatic actions of juvenile hormone. Insect Biochemistry and Molecular Biology. 2007; 37:761-770. [PubMed: 17628276]

19. Dominick OS, Truman JW. The physiology of wandering behaviour in Manduca sexta. II. The endocrine control of wandering behaviour. Journal of Experimental Biology. 1985; 117:45-68. [PubMed: 4067505]

20. McBrayer Z, Ono H, Shimell M, Parvy J-P, Beckstead RB, Warren JT, Thummel CS, DauphinVillemant C, Gilbert LI, O'Connor MB. Prothoracicotropic hormone regulates developmental timing and body size in Drosophila. Developmental Cell. 2007; 13:857-871. [PubMed: 18061567]

Wiley Interdiscip Rev Dev Biol. Author manuscript; available in PMC 2015 January 01. 
21. Nijhout HF, Williams CM. Control of moulting and metamorphosis in the tobacco hornworm, Manduca sexta $(\mathrm{L})$ : cessation of juvenile hormone secretion as a trigger for pupation. Journal of Experimental Biology. 1974; 61:493-501. [PubMed: 4443741]

22. Truman JW, Riddiford LM. Physiology of insect rhythms. 3. The temporal organization of the endocrine events underlying pupation of the tobacco hornworm. Journal of Experimental Biology. 1974; 60:371-382. [PubMed: 4832987]

23. Riddiford LM. Ecdysone-induced change in cellular commitment of the epidermis of the tobacco hornworm, Manduca sexta, at the initiation of metamorphosis. General and Comparative Endocrinology. 1978; 34:438-446. [PubMed: 648872]

24. Wigglesworth V. The determination of characters at metamorphosis in Rhodnius prolixus (Hemiptera). Journal of Experimental Biology. 1940; 17:201-223.

25. Riddiford LM. Hormonal control of insect epidermal cell commitment in vitro. Nature. 1976; 259:115-117. [PubMed: 1246347]

26. Wigglesworth V. Local and general factors in the development of "pattern" in Rhodnius prolixus (Hemiptera). Journal of Experimental Biology. 1940; 17:180-200.

27. Truman, JW. Hormonal control of the form and function of the nervous system. In: Gilbert, LI.; Iatrou, K.; Gill, SS., editors. Comprehensive Molecular Insect Science. Vol. 2. Oxford: Elsevier; 2005. p. 135-163.

28. Nijhout HF, Davidowitz G, Roff DA. A quantitative analysis of the mechanism that controls body size in Manduca sexta. Journal of Biology. 2006; 5:16. [PubMed: 16879739]

29. Mirth C, Truman J, Riddiford L. The role of the prothoracic gland in determining critical weight for metamorphosis in Drosophila melanogaster. Current Biology. 2005; 15:1796-1807. [PubMed: 16182527]

30. de Jong G, Bochdanovits Z. Latitudinal clines in Drosophila melanogaster: body size, allozyme frequencies, inversion frequencies and the insulin-signalling pathway. Journal of Genetics. 2003; 82:207-223. [PubMed: 15133196]

31. James AC, Azevedo RB, Partridge L. Genetic and environmental responses to temperature of Drosophila melanogaster from a latitudinal cline. Genetics. 1997; 146:881-890. [PubMed: 9215894]

32. Partridge L, Barrie B, Fowler K, French V. Evolution and development of body size and cell size in Drosophila melanogaster in response to temperature. Evolution. 1994; 48:1269-1276.

33. James AC, Partridge L. Thermal evolution of rate of larval development in Drosophila melanogaster in laboratory and field populations. Journal of Evolutionary Biology. 1995; 8:315330.

34. James AC, Azevedo RB, Partridge L. Cellular basis and developmental timing in a size cline of Drosophila melanogaster. Genetics. 1995; 140:659-666. [PubMed: 7498744]

35. Ray C. The application of Bergmann's and Allen's Rules to the poikilotherms. Journal of Morphology. 1960; 106:85-108. [PubMed: 14436612]

36. Arnett AE, Gotelli NJ. Geographic variation in life-history traits of the ant lion, Myrmeleon immaculatus: evolutionary implications of Bergmann's rule. Evolution. 1999; 53:1180-1188.

37. Blanckenhorn WU, Demont M. Bergmann and converse Bergmann latitudinal clines in arthropods: two ends of a continuum? Integrative and Comparative Biology. 2004; 44:413-424. [PubMed: 21676727]

38. Partridge L, Barrie B, Fowler K, French V. Thermal evolution of pre-adult life-history traits in Drosophila melanogaster. Journal of Evolutionary Biology. 1994; 7:645-663.

39. Fabian DK, Kapun M, Nolte V, Kofler R, Schmidt PS, Schlötterer C, Flatt T. Genome-wide patterns of latitudinal differentiation among populations of Drosophila melanogaster from North America. Molecular Ecology. 2012; 21:4748-4769. [PubMed: 22913798]

40. Gockel J, Kennington WJ, Hoffmann A, Goldstein DB, Partridge L. Nonclinality of molecular variation implicates selection in maintaining a morphological cline of Drosophila melanogaster. Genetics. 2001; 158:319-323. [PubMed: 11333239]

41. Hoffmann AA, Weeks AR. Climatic selection on genes and traits after a 100-year-old invasion: a critical look at the temperate-tropical clines in Drosophila melanogaster from eastern Australia. Genetica. 2007; 129:133-147. [PubMed: 16955331] 
42. Knibb WR, Oakeshott JG, Gibson JB. Chromosome inversion polymorphisms in Drosophila melanogaster. I. latitudinal clines and associations between inversions in Australasian populations. Genetics. 1981; 98:833-847. [PubMed: 17249108]

43. Mettler LE, Voelker RA, Mukai T. Inversion clines in populations of Drosophila melanogaster. Genetics. 1977; 87:169-176. [PubMed: 17248756]

44. Weeks AR, McKechnie SW, Hoffmann AA. Dissecting adaptive clinal variation: markers, inversions and size/stress associations in Drosophila melanogaster from a central field population. Ecology Letters. 2002; 5:756-763.

45. Lee SF, Chen Y, Varan AK, Wee CW, Rako L, Axford JK, Good RT, Blacket MJ, Reuter C, Partridge L, et al. Molecular basis of adaptive shift in body size in Drosophila melanogaster: functional and sequence analyses of the Dca gene. Molecular Biology and Evolution. 2011; 28:2393-2402. [PubMed: 21393605]

46. McKechnie SW, Blacket MJ, Song SV, Rako L, Carroll X, Johnson TK, Jensen LT, Lee SF, Wee $\mathrm{CW}$, Hoffmann AA. A clinally varying promoter polymorphism associated with adaptive variation in wing size in Drosophila. Molecular Ecology. 2010; 19:775-784. [PubMed: 20074315]

47. Beadle GW, Tatum EL, Clancy CW. Food level in relation to rate of development and eye pigmentation in Drosophila melanogaster. The Biological Bulletin. 1938; 75:447-462.

48. Robertson FW. The ecological genetics of growth in Drosophila 6. The genetic correlation between the duration of the larval period and body size in relation to larval diet. Genetics Research. 1963; 4:74-92.

49. French V, Feast M, Partridge L. Body size and cell size in Drosophila: the developmental response to temperature. Journal of Insect Physiology. 1998; 44:1081-1089. [PubMed: 12770407]

50. Robinson SJW, Partridge L. Temperature and clinal variation in larval growth efficiency in Drosophila melanogaster. Journal of Evolutionary Biology. 2001; 14:14-21.

51. Santos M, Fowler K, Partridge L. Gene-environment interaction for body size and larval density in Drosophila melanogaster: an investigation of effects on development time, thorax length and adult sex ratio. Heredity. 1994; 72:515-521. [PubMed: 8014062]

52. Nunney L, Cheung W. The effect of temperature on body size and fecundity in female Drosophila melanogaster: evidence for adaptive plasticity. Evolution. 1997; 51:1529-1535.

53. DiAngelo JR, Bland ML, Bambina S, Cherry S, Birnbaum MM. The immune response attenuates growth and nutrient storage in Drosophila by reducing insulin signaling. Proceedings of the National Academy of Sciences. 2009; 106:20853-20858.

54. Ikeya T, Broughton S, Alic N, Grandison RC, Partridge L. The endosymbiont Wolbachia increases insulin/IGF-like signalling in Drosophila. Proceedings of the Royal Society B: Biological Sciences. 2009; 276:3799-3807.

55. Storelli G, Defaye A, Erkosar B, Hols P, Royet J, Leulier F. Lactobacillus plantarum promotes Drosophila systemic growth by modulating hormonal signals through TOR-dependent nutrient sensing. Cell Metabolism. 2011; 14:403-414. [PubMed: 21907145]

56. Simpson P, Berreur P, Berreur-Bonnenfant J. The initiation of pupariation in Drosophila: dependence on growth of the imaginal discs. J Embryol Exp Morphol. 1980; 57:155-165. [PubMed: 7430927]

57. Stieper BC, Kupershtok M, Driscoll MV, Shingleton AW. Imaginal discs regulate developmental timing in Drosophila melanogaster. Developmental Biology. 2008; 321:18-26. [PubMed: 18632097]

58. Halme A, Cheng M, Hariharan IK. Retinoids regulate a developmental checkpoint for tissue regeneration in Drosophila. Current Biology. 2010; 20:458-463. [PubMed: 20189388]

59. Peck LS, Maddrell SHP. Limitation of size by hypoxia in the fruit fly Drosophila melanogaster. J Exp Zool Part A. 2005; 303A:968-975.

60. Lazebnyi OE, Zakharchuck EV, Imasheva AG. Larval density and variation of body size in laboratory lines of Drosophila melanogaster. Russian Journal of Genetics. 1996; 32:883-884.

61. Shin SC, Kim S-H, You H, Kim B, Kim AC, Lee K-A, Yoon J-H, Ryu J-H, Lee W-J. Drosophila microbiome modulates host developmental and metabolic homeostasis via insulin signaling. Science. 2011; 334:670-674. [PubMed: 22053049] 
62. Ghosh SM, Testa ND, Shingleton AW. Temperature-size rule is mediated by thermal plasticity of critical size in Drosophila melanogaster. Proceedings of the Royal Society B: Biological Sciences. 2013; 280:20130174.

63. Colombani J, Raisin S, Pantalacci S, Radimerski T, Montagne J, Leopold P. A nutrient sensor mechanism controls Drosophila growth. Cell. 2003; 114:739-749. [PubMed: 14505573]

64. Nobukuni T, Joaquin M, Roccio M, Dann SG, Kim SY, Gulati P, Byfield MP, Backer JM, Natt F, Bos JL, et al. Amino acids mediate mTOR/raptor signaling through activation of class 3 phosphatidylinositol 3OH-kinase. Proceedings of the National Academy of Sciences. 2005; 102:14238-14243.

65. Zhang H, Stallock JP, Ng JC, Reinhard C, Neufeld TP. Regulation of cellular growth by the Drosophila target of rapamycin dTOR. Genes \& Development. 2000; 14:2712-2724. [PubMed: 11069888]

66. Tennessen JM, Thummel CS. Coordinating growth and maturation - insights from Drosophila. Current Biology. 2011; 21:750-757.

67. Britton JS, Lockwood WK, Li L, Cohen SM, Edgar BA. Drosophila's insulin/P13-kinase pathway coordinates cellular metabolism with nutritional conditions. Developmental Cell. 2002; 2:239_ 249. [PubMed: 11832249]

68. Brogiolo W, Stocker H, Ikeya T, Rintelen F, Fernandez R, Hafen E. An evolutionarily conserved function of the Drosophila insulin receptor and insulin-like peptides in growth control. Current Biology. 2001; 11:213-221. [PubMed: 11250149]

69. Chen C, Jack J, Garofalo RS. The Drosophila insulin receptor is required for normal growth. Endocrinology. 1996; 137:846-856. [PubMed: 8603594]

70. Ikeya T, Galic M, Belawat P, Nairz K, Hafen E. Nutrient-dependent expression of insulin-like peptides from neuroendocrine cells in the CNS contributes to growth regulation in Drosophila. Current Biology. 2002; 12:1293-1300. [PubMed: 12176357]

71. Oldham S, Hafen E. Insulin/IGF and target of rapamycin signaling: a TOR de force in growth control. Trends in Cell Biology. 2003; 13:79-85. [PubMed: 12559758]

72. Puig O, Tjian R. Nutrient availability and growth: regulation of insulin signaling by dFOXO/ FOXO1. Cell Cycle. 2006; 5:503-505. [PubMed: 16552183]

73. Kim D-H, Sarbassov DD, Ali SM, King JE, Latek RR, Erdjument-Bromage H, Tempst P, Sabatini DM. mTOR interacts with raptor to form a nutrient-sensitive complex that signals to the cell growth machinery. Cell. 2002; 110:163-175. [PubMed: 12150925]

74. Oldham S, Montagne J, Radimerski T, Thomas G, Hafen E. Genetic and biochemical characterization of dTOR, the Drosophila homolog of the target of rapamycin. Genes \& Development. 2000; 14:2689-2694. [PubMed: 11069885]

75. Grewal SS. Insulin/TOR signaling in growth and homeostasis: A view from the fly world. International Journal of Biochemistry and Cell Biology. 2009; 41:1006-1010. [PubMed: 18992839]

76. Masumura M, Satake SI, Saegusa H, Mizoguchi A. Glucose stimulates the release of bombyxin, an insulin-related peptide of the silkworm Bombyx mori. General and Comparative Endocrinology. 2000; 118:393-399. [PubMed: 10843790]

77. Rulifson EJ, Kim SK, Nusse R. Ablation of insulin-producing neurons in flies: growth and diabetic phenotypes. Science. 2002; 296:1118-1120. [PubMed: 12004130]

78. Géminard C, Rulifson EJ, Léopold P. Remote control of insulin secretion by fat cells in Drosophila. Cell Metabolism. 2009; 10:199-207. [PubMed: 19723496]

79. Bohni R, Riesgo-Escovar J, Oldham S, Brogiolo W, Stocker H, Andruss BF, Beckingham K, Hafen E. Autonomous control of cell and organ size by CHICO, a Drosophila homolog of vertebrate IRS1-4. Cell. 1999; 97:865-875. [PubMed: 10399915]

80. Weinkove D, Neufeld TP, Twardzik T, Waterfield MD, Leevers SJ. Regulation of imaginal disc cell size, cell number and organ size by Drosophila class IA phosphoinositide 3-kinase and its adaptor. Current Biology. 1999; 9:1019-1029. [PubMed: 10508611]

81. Goberdhan DCI, Paricio N, Goodman EC, Mlodzik M, Wilson C. Drosophila tumor suppressor PTEN controls cell size and number by antagonizing the Chico/PI3-kinase signaling pathway. Genes \& Development. 1999; 13:3244-3258. [PubMed: 10617573] 
82. Gao X, Neufeld TP, Pan D. Drosophila PTEN regulates cell growth and proliferation through PI3K-dependent and independent pathways. Developmental Biology. 2000; 221:404-418. [PubMed: 10790335]

83. Huang H, Potter CJ, Tao W, Li DM, Brogiolo W, Hafen E, Sun H, Xu T. PTEN affects cell size, cell proliferation and apoptosis during Drosophila eye development. Development. 1999; 126:5365-5372. [PubMed: 10556061]

84. Verdu J, Buratovich MA, Wilder EL, Birnbaum MJ. Cell-autonomous regulation of cell and organ growth in Drosophila by Akt/PKB. Nature Cell Biol. 1999; 1:500-506. [PubMed: 10587646]

85. Kramer J, Davidge J, Lockyer J, Staveley B. Expression of Drosophila FOXO regulates growth and can phenocopy starvation. BMC Developmental Biology. 2003; 3:5. [PubMed: 12844367]

86. Puig O, Marr MT, Ruhf ML, Tjian R. Control of cell number by Drosophila FOXO: downstream and feedback regulation of the insulin receptor pathway. Genes \& Development. 2003; 17:20062020. [PubMed: 12893776]

87. Kim SK, Rulifson EJ. Conserved mechanisms of glucose sensing and regulation by Drosophila corpora cardiaca cells. Nature. 2004; 431:316-320. [PubMed: 15372035]

88. Chell JM, Brand AH. Nutrition-responsive glia control exit of neural stem cells from quiescence. Cell. 2010; 143:1161-1173. [PubMed: 21183078]

89. Sousa-Nunes R, Yee LL, Gould AP. Fat cells reactivate quiescent neuroblasts via TOR and glial insulin relays in Drosophila. Nature. 2011; 471:508-512. [PubMed: 21346761]

90. Rajan A, Perrimon N. Drosophila cytokine unpaired 2 regulates physiological homeostasis by remotely controlling insulin secretion. Cell. 2012; 151:123-137. [PubMed: 23021220]

91. Honegger B, Galic M, Kohler K, Wittwer F, Brogiolo W, Hafen E, Stocker H. Imp-L2, a putative homolog of vertebrate IGF-binding protein 7, counteracts insulin signaling in Drosophila and is essential for starvation resistance. Journal of Biology. 2008; 7:10-10. [PubMed: 18412985]

92. Osterbur DL, Fristrom DK, Natzle JE, Tojo SJ, Fristrom JW. Genes expressed during imaginal discs morphogenesis: IMP-L2, a gene expressed during imaginal disc and imaginal histoblast morphogenesis. Developmental Biology. 1988; 129:439-448. [PubMed: 2843403]

93. Okamoto N, Nakamori R, Murai T, Yamauchi Y, Masuda A, Nishimura T. A secreted decoy of InR antagonizes insulin/IGF signaling to restrict body growth in Drosophila. Genes \& Development. 2013; 27:87-97. [PubMed: 23307869]

94. Henrich, VC. The ecdysteroid receptor. In: Gilbert, LI., editor. Insect Endocrinology. London: Academic Press; 2012. p. 177-218.

95. Charles J-P, Iwema T, Epa V, Takaki K, Rynes J, Jindra M. Ligand-binding properties of a juvenile hormone receptor, Methoprene-tolerant. Proceedings of the National Academy of Sciences. 2011; 108:21128-21133.

96. Jindra M, Palli SR, Riddiford LM. The juvenile hormone signaling pathway in insect development. Annual Review of Entomology. 2013; 58:181-204.

97. Baumann A, Fujiwara Y, Wilson TG. Evolutionary divergence of the paralogs Methoprene tolerant (Met) and germ cell expressed (gce) within the genus Drosophila. Journal of Insect Physiology. 2010; 56:1445-1455. [PubMed: 20457161]

98. Baumann AA, Barry J, Wang S, Fujiwara Y, Wilson TG. Paralogous genes involved in juvenile hormone action in Drosophila melanogaster. Genetics. 2010; 185:1327-1336. [PubMed: 20498297]

99. Godlewski J, Wang S, Wilson TG. Interaction of bHLH-PAS proteins involved in juvenile hormone reception in Drosophila. Biochemical and Biophysical Research Communications. 2006; 342:1305-1311. [PubMed: 16516852]

100. Abdou MA, He Q, Wen D, Zyaan O, Wang J, Xu J, Baumann AA, Joseph J, Wilson TG, Li S, et al. Drosophila Met and Gce are partially redundant in transducing juvenile hormone action. Insect Biochemistry and Molecular Biology. 2011; 41:938-945. [PubMed: 21968404]

101. Liu Y, Sheng Z, Liu H, Wen D, He Q, Wang S, Shao W, Jiang R-J, An S, Sun Y, et al. Juvenile hormone counteracts the bHLH-PAS transcription factors MET and GCE to prevent caspasedependent programmed cell death in Drosophila. Development. 2009; 136:2015-2025. [PubMed: 19465595] 
102. Layalle S, Arquier N, Léopold P. The TOR pathway couples nutrition and developmental timing in Drosophila. Developmental Cell. 2008; 15:568-577. [PubMed: 18854141]

103. Caldwell PE, Walkiewicz M, Stern M. Ras activity in the Drosophila prothoracic gland regulates body size and developmental rate via ecdysone release. Current Biology. 2005; 15:1785-1795. [PubMed: 16182526]

104. Walkiewicz MA, Stern M. Increased insulin/insulin growth factor signaling advances the onset of metamorphosis in Drosophila. PLoS One. 2009; 4:e5072. [PubMed: 19352497]

105. Delanoue R, Slaidina M, Léopold P. The steroid hormone ecdysone controls systemic growth by repressing dMyc function in Drosophila fat cells. Developmental Cell. 2010; 18:1012-1021. [PubMed: 20627082]

106. Francis VA, Zorzano A, Teleman AA. dDOR is an EcR coactivator that forms a feed-forward loop connecting insulin and ecdysone signaling. Current Biology. 2010; 20:1799-1808. [PubMed: 20888228]

107. Mirth CK, Truman JW, Riddiford LM. The ecdysone receptor controls the post-critical weight switch to nutrition-independent differentiation in Drosophila wing imaginal discs. Development. 2009; 136:2345-2353. [PubMed: 19515698]

108. Parker NF, Shingleton AW. The coordination of growth among Drosophila organs in response to localized growth-perturbation. Developmental Biology. 2011; 357:318-325. [PubMed: 21777576]

109. Nijhout HF, Grunert LW. The cellular and physiological mechanism of wing-body scaling in Manduca sexta. Science. 2010; 330:1693-1695. [PubMed: 21109634]

110. Kato Y, Riddiford L. The role of 20-hydroxyecdysone in stimulating epidermal mitoses during the larval-pupal transformation of the tobacco hornworm, Manduca sexta. Development. 1987; 100:227-236.

111. Truman JW, Hiruma K, Allee JP, Macwhinnie SG, Champlin DT, Riddiford LM. Juvenile hormone is required to couple imaginal disc formation with nutrition in insects. Science. 2006; 312:1385-1388. [PubMed: 16741122]

112. Riddiford LM, Truman JW, Mirth CK, Shen Y-c. A role for juvenile hormone in the prepupal development of Drosophila melanogaster. Development. 2010; 137:1117-1126. [PubMed: 20181742]

113. Garelli A, Gontijo AM, Miguela V, Caparros E, Dominguez M. Imaginal discs secrete InsulinLike Peptide 8 to mediate plasticity of growth and maturation. Science. 2012; 336:579-582. [PubMed: 22556250]

114. Colombani J, Andersen DS, Leopold P. Secreted peptide DILP8 coordinates Drosophila tissue growth with developmental timing. Science. 2012; 336:582-585. [PubMed: 22556251]

115. Sehnal F, Bryant PJ. Delayed pupariation in Drosophila imaginal disc overgrowth mutants is associated with reduced ecdysteroid titer. Journal of Insect Physiology. 1993; 39:1051-1059.

116. Atkinson, D. Temperature and organism size--a biological law for ectotherms?. In: Begon, M.; Fitter, AH., editors. Advances in Ecological Research. Vol. 25. Academic Press; 1994. p. 1-58.

117. Davidowitz G, Nijhout HF. The physiological basis of reaction norms: the interaction among growth rate, the duration of growth and body size. Integrative and Comparative Biology. 2004; 44:443-449. [PubMed: 21676730]

118. Callier V, Nijhout HF. Control of body size by oxygen supply reveals size-dependent and sizeindependent mechanisms of molting and metamorphosis. Proceedings of the National Academy of Sciences. 2011; 108:14664-14669.

119. Greenlee KJ, Harrison JF. Respiratory changes throughout ontogeny in the tobacco hornworm caterpillar, Manduca sexta. The Journal of Experimental Biology. 2005; 208:1385-1392. [PubMed: 15781898]

120. Okamoto N, Yamanaka N, Yagi Y, Nishida Y, Kataoka H, O'Connor MB, Mizoguchi A. A fat body-derived IGF-like peptide regulates postfeeding growth in Drosophila. Developmental Cell. 2009; 17:885-891. [PubMed: 20059957]

121. Slaidina M, Delanoue R, Gronke S, Partridge L, Léopold P. A Drosophila insulin-like peptide promotes growth during nonfeeding states. Developmental Cell. 2009; 17:874-884. [PubMed: 20059956] 
122. Okamoto N, Yamanaka N, Satake H, Saegusa H, Kataoka H, Mizoguchi A. An ecdysteroidinducible insulin-like growth factor-like peptide regulates adult development of the silkmoth Bombyx mori. FEBS Journal. 2009; 276:1221-1232. [PubMed: 19175674]

123. Agui N, Granger NA, Gilbert LI, Bollenbacher WE. Cellular localization of the insect prothoracicotropic hormone: In vitro assay of a single neurosecretory cell. Proceedings of the National Academy of Sciences. 1979; 76:5694-5698.

124. Smith, WA.; Rybczynski, R. Prothoracicotropic hormone. In: Gilbert, LI., editor. Insect Endocrinology. London: Academic Press; 2012. p. 1-62.

125. Rewitz K, Yamanaka N, Gilbert L, O’Connor M. The insect neuropeptide PTTH activates receptor tyrosine kinase Torso to initiate metamorphosis. Science. 2009; 326:1403-1405. [PubMed: 19965758]

126. Wigglesworth V. The physiology of ecdysis in Rhodnius prolixus (Hemiptera). II. Factors controlling moulting and 'metamorphosis'. Quarterly Journal of Microscopic Science. 1934; 77:191-222.

127. Nijhout HF. Abdominal stretch reception in Dipetalogaster maximus (Hemiptera: Reduviidae). Journal of Insect Physiology. 1984; 30:629-633.

128. Nijhout HF. Stretch-induced moulting in Oncopeltus fasciatus. Journal of Insect Physiology. $1979 ; 25: 277-282$.

129. Davidowitz G, D'Amico LJ, Nijhout HF. The effects of environmental variation on a mechanism that controls insect body size. Evolutionary Ecology Research. 2004; 6:49-62.

130. Davidowitz G, D'Amico LJ, Nijhout HF. Critical weight in the development of insect body size. Evolution \& Development. 2003; 5:188-197. [PubMed: 12622736]

131. Nijhout HF, Williams CM. Control of moulting and metamorphosis in the tobacco hornworm, Manduca sexta (L): growth of the last-instar larva and the decision to pupate. Journal of Experimental Biology. 1974; 61:481-491. [PubMed: 4443740]

132. Truman JW. Physiology of insect rhythms. 1, Circadian organization of the endocrine events underlying the molting cycle of larval tobacco hornworms. Journal of Experimental Biology. 1972; 57:805-820.

133. Rountree D, Bollenbacher W. Juvenile hormone regulates ecdysone secretion through inhibition of PTTH release. American Zoologist. 1984; 24:A31.

134. Rountree D, Bollenbacher W. The release of the prothoracicotropic hormone in the tobacco hornworm, Manduca sexta, is controlled intrinsically by juvenile hormone. Journal of Experimental Biology. 1986; 120:41-58. [PubMed: 3958672]

135. Sakurai S, Okuda M, Ohtaki T. Juvenile hormone inhibits ecdysone secretion and responsiveness to prothoracicotropic hormone in prothoracic glands of Bombyx mori. General and Comparative Endocrinology. 1989; 75:222-230. [PubMed: 2806872]

136. Dominick OS, Truman JW. The physiology of wandering behavior In Manduca-sexta. 1. Temporal organization and the influence of the internal and external environments. Journal of Experimental Biology. 1984; 110:35-51. [PubMed: 6540290]

137. Nijhout HF. Dynamics of juvenile hormone action in larvae of the tobacco hornworm, Manduca sexta (L). The Biological Bulletin. 1975; 149:568-579. [PubMed: 1203337]

138. Truman JW, Riddiford LM, Safranek L. Temporal patterns of response to ecdysone and juvenile hormone in the epidermis of the tobacco hornworm, Manduca sexta. Developmental Biology. 1974; 39:247-262. [PubMed: 4854621]

139. Cymborowski B, Bogus M, Beckage NE, Williams CM, Riddiford LM. Juvenile-hormone titers and metabolism during starvation-induced supernumerary larval molting of the tobacco hornworm Manduca sexta L. Journal of Insect Physiology. 1982; 28:129-135.

140. Riddiford LM, Ashburner M. Effects of juvenile hormone mimics on larval development and metamorphosis of Drosophila melanogaster. General and Comparative Endocrinology. 1991; 82:172-183. [PubMed: 1906823]

141. Zhou X, Riddiford LM. Broad specifies pupal development and mediates the status quo action of juvenile hormone on the pupal-adult transformation in Drosophila and Manduca. Development. 2002; 129:2259-2269. [PubMed: 11959833] 
142. Shafiei M, Moczek AP, Nijhout HF. Food availability controls the onset of metamorphosis in the dung beetle Onthophagus taurus (Coleoptera: Scarabaeidae). Physiological Entomology. 2001; 26:173-180.

143. Fukuda S. The hormonal mechanism of larval molting and metamorphosis in the silkworm. Journal of the Faculty of Science Tokyo Imperial University. 1944; 4:477-532.

144. Dean RL, Bollenbacher WE, Locke M, Smith SL, Gilbert LI. Haemolymph ecdysteroid levels and cellular events in the intermoult/moult sequence of Calpodes ethlius. Journal of Insect Physiology. 1980; 26:267-280.

145. Rountree DB, Nijhout HF. Hormonal control of a seasonal polyphenism in Precis coenia (Lepidoptera: Nymphalidae). Journal of Insect Physiology. 1995; 41:987-992.

146. Gu S-H, Young S-C, Lin J-L, Lin P-L. Involvement of PI3K/Akt signaling in PTTH-stimulated ecdysteroidogenesis by prothoracic glands of the silkworm, Bombyx mori. Insect Biochemistry and Molecular Biology. 2011; 41:197-202. [PubMed: 21199670]

147. Tanaka Y. Recent topics on the regulatory mechanism of ecdysteroidogenesis by the prothoracic gland in insects. Frontiers in Endocrinology. 2011; 107:1-6.

148. Locke, M. Epidermis. In: Harrison, FW.; Locke, M., editors. Microscopic Anatomy of Invertebrates. New York: Wiley Liss \& Sons; 1998. p. 75-138.

149. Locke M. The Wigglesworth Lecture: Insects for studying fundamental problems in biology. Journal of Insect Physiology. 2001; 47:495-507. [PubMed: 11166314]

150. Ashburner M, Chihara C, Meltzer P, Richards G. Temporal control of puffing activity in polytene chromosomes. Cold Spring Harbor Symposia on Quantitative Biology. 1974; 38:655-662.

151. Hill RJ, Billas IML, Bonneton F, Graham LD, Lawrence MC. Ecdysone receptors: from the Ashburner model to structural biology. Annual Review of Entomology. 2013; 58:251-271.

152. Koelle MR, Talbot WS, Segraves WA, Bender MT, Cherbas P, Hogness DS. The Drosophila EcR gene encodes an ecdysone receptor, a new member of the steroid receptor superfamily. Cell. 1991; 67:59-77. [PubMed: 1913820]

153. Yao TP, Segraves WA, Oro AE, McKeown M, Evans RM. Drosophila Ultraspiracle modulates ecdysone receptor function via heterodimer formation. Cell. 1992; 71:63-72. [PubMed: 1327536]

154. Hiruma K, Riddiford L. Developmental expression of mRNAs for epidermal and fat body proteins and hormonally regulated transcription factors in the tobacco hornworm, Manduca sexta. Journal of Insect Physiology. 2010; 56:1390-1395. [PubMed: 20361974]

155. Langelan RE, Fisher JE, Hiruma K, Palli SR, Riddiford LM. Patterns of MHR3 expression in the epidermis during a larval molt of the tobacco hornworm Manduca sexta. Developmental Biology. 2000; 227:481-494. [PubMed: 11071768]

156. Warren J, Yerushalmi Y, Shimell M, O’Connor M, Restifo L, Gilbert L. Discrete pulses of molting hormone, 20-hydroxyecdysone, during late larval development of Drosophila melanogaster: Correlations with changes in gene activity. Developmental Dynamics. 2006; 235:315-326. [PubMed: 16273522]

157. Schubiger M, Truman JW. The RXR ortholog USP suppresses early metamorphic processes in Drosophila in the absence of ecdysteroids. Development. 2000; 127:1151-1159. [PubMed: 10683169]

158. Bayer CA, Holley B, Fristrom JW. A switch in Broad-Complex zinc-finger isoform expression is regulated posttranscriptionally during the metamorphosis of Drosophila imaginal discs. Developmental Biology. 1996; 177:1-14. [PubMed: 8660872]

159. Zhou B, Hiruma K, Shinoda T, Riddiford L. Juvenile hormone prevents ecdysteroid-induced expression of Broad Complex RNAs in the epidermis of the tobacco hornworm, Manduca sexta. Developmental Biology. 1998; 203:233-244. [PubMed: 9808776]

160. Zhou B, Riddiford LM. Hormonal regulation and patterning of the Broad-Complex in the epidermis and wing discs of the tobacco hornworm, Manduca sexta. Developmental Biology. 2001; 231:125-137. [PubMed: 11180957]

161. Champlin DT, Reiss SE, Truman JW. Hormonal control of ventral diaphragm myogenesis during metamorphosis of the moth, Manduca sexta. Development, Genes and Evolution. 1999; 209:265-274. [PubMed: 11252179] 
162. Champlin DT, Truman JW. Ecdysteroid control of cell proliferation during optic lobe neurogenesis in the moth Manduca sexta. Development. 1998; 125:269-277. [PubMed: 9486800]

163. Talbot WS, Swyryd EA, Hogness DS. Drosophila tissues with different metamorphic responses to ecdysone express different ecdysone receptor isoforms. Cell. 1993; 73:1323-1337. [PubMed: 8324824]

164. Truman JW, Talbot WS, Fahrbach SE, Hogness DS. Ecdysone receptor expression in the CNS correlates with stage-specific responses to ecdysteroids during Drosophila and Manduca development. Development. 1994; 120:219-234. [PubMed: 8119129]

165. Wilson TG, Ashok M. Insecticide resistance resulting from an absence of target-site gene product. Proceedings of the National Academy of Sciences. 1998; 95:14040-14044.

166. Goodman, WG.; Granger, NA. The juvenile hormones. In: Lawrence, I.; Gilbert, LI.; Iatrou, K.; Gill, SS., editors. Comprehensive Molecular Insect Science. Amsterdam: Elsevier; 2005. p. 319-408.

167. Hiruma K, Kaneko Y. Hormonal regulation of insect metamorphosis with special reference to juvenile hormone biosynthesis. Current Topics in Developmental Biology. 2013; 103:73-100. [PubMed: 23347516]

168. Belles X, Martin D, Piulachs MD. The mevalonate pathway and the synthesis of juvenile hormone in insects. Annual Review of Entomology. 2005; 50:181-199.

169. Jones G, Teal P, Henrich VC, Krzywonos A, Sapa A, Wozniak M, Smolka J, Jones D. Ligand binding pocket function of Drosophila USP is necessary for metamorphosis. General and Comparative Endocrinology. 2013; 182:73-82. [PubMed: 23211750]

170. Jones G, Jones D, Teal P, Sapa A, Wozniak M. The retinoid-X receptor ortholog, ultraspiracle, binds with nanomolar affinity to an endogenous morphogenetic ligand. FEBS Journal. 2006; 273:4983-4996. [PubMed: 17064257]

171. Minakuchi C, Namiki T, Yoshiyama M, Shinoda T. RNAi-mediated knockdown of juvenile hormone acid O-methyltransferase gene causes precocious metamorphosis in the red flour beetle Tribolium castaneum. FEBS Journal. 2008; 275:2919-2931. [PubMed: 18435763]

172. Daimon T, Kozaki T, Niwa R, Kobayashi I, Furuta K, Namiki T, Uchino K, Banno Y, Katsuma S, Tamura T, et al. Precocious metamorphosis in the juvenile hormone-deficient mutant of the silkworm, Bombyx mori. PLoS Genetics. 2012:8.

173. Kataoka H, Toschi A, Li JP, Carney RL, Schooley DA, Kramer SJ. Identification of an allatotropin from adult Manduca sexta. Science (New York, NY). 1989; 243:1481-1483.

174. Yamanaka N, Yamamoto S, Zitnan D, Watanabe K, Kawada T, Satake H, Kaneko Y, Hiruma K, Tanaka Y, Shinoda T, et al. Neuropeptide receptor transcriptome reveals unidentified neuroendocrine pathways. PLoS ONE. 2008; 3:e3048. [PubMed: 18725956]

175. Wang C, Zhang J, Tobe SS, Bendena WG. Defining the contribution of select neuropeptides and their receptors in regulating sesquiterpenoid biosynthesis by Drosophila melanogaster ring gland/corpus allatum through RNAi analysis. General and Comparative Endocrinology. 2012; 176:347-353. [PubMed: 22245290]

176. Chiang AS, Lin WY, Liu HP, Pszczolkowski MA, Fu TF, Chiu SL, Holbrook GL. Insect NMDA receptors mediate juvenile hormone biosynthesis. Proceedings of the National Academy of Sciences. 2002; 99:37-42.

177. Huang JH, Tian L, Peng C, Abdou M, Wen D, Wang Y, Li S, Wang J. DPP-mediated TGF beta signaling regulates juvenile hormone biosynthesis by activating the expression of juvenile hormone acid methyltransferase. Development. 2011; 138:2283-2291. [PubMed: 21558376]

178. Granger NA, Sturgis SL, Ebersohl R, Geng C, Sparks TC. Dopaminergic control of corpora allata activity in the larval tobacco hornworm, Manduca sexta. Archives of Insect Biochemistry and Physiology. 1996; 32:449-466. [PubMed: 8756306]

179. Hammock, BD. Regulation of juvenile hormone titer: degradation. In: Kerkut, GA.; Gilbert, LI., editors. Comprehensive Insect Physiology, Biochemistry, and Pharmacology. New York: Pergamon Press; 1985. p. 431-472. 
180. Kamita SG, Hinton AC, Wheelock CE, Wogulis MD, Wilson DK, Wolf NM, Stok JE, Hock B, Hammock BD. Juvenile hormone $(\mathrm{JH})$ esterase: why are you so JH specific? Insect Biochemistry and Molecular Biology. 2003; 33:1261-1273. [PubMed: 14599498]

181. de Kort CAD, Granger NA. Regulation of JH titers: The relevance of degradative enzymes and binding proteins. Archives of Insect Biochemistry and Physiology. 1996; 33:1-26.

182. Sparks TC, Hammock BD, Riddiford LM. The hemolymph juvenile-hormone esterase of Manduca-sexta (L) - inhibition and regulation. Insect Biochemistry. 1983; 13:529-541.

183. Browder MH, D'Amico LJ, Nijhout HF. The role of low levels of juvenile hormone esterase in the metamorphosis of Manduca sexta. Journal of Insect Science. 2001; 1:11. [PubMed: 15455071]

184. Mitsui T, Riddiford LM, Bellamy G. Metabolism of juvenile hormone by the epidermis of the tobacco hornworm, Manduca sexta. Insect Biochemistry. 1979; 9:637-643.

185. Sparks TC, Hammock BD. Comparative inhibition of the juvenile hormone esterases from Trichoplusia ni, Tenebrio molitor, and Musca domestica. Pesticide Biochemistry and Physiology. 1980; 14:290-302.

186. Seino A, Ogura T, Tsubota T, Shimomura M, Nakakura T, Tan A, Mita K, Shinoda T, Nakagawa Y, Shiotsuki T. Characterization of juvenile hormone epoxide hydrolase and related genes in the larval development of the silkworm Bombyx mori. Bioscience Biotechnology and Biochemistry. 2010; 74:1421-1429.

187. Goodman W, O'Hern PA, Zaugg RH, Gilbert LI. Purification and characterization of a juvenile hormone binding protein from the hemolymph of the fourth instar tobacco hornworm, Manduca sexta. Molecular and Cellular Endocrinology. 1978; 11:225-242. [PubMed: 680342]

188. Konopova B, Jindra M. Juvenile hormone resistance gene Methoprene-tolerant controls entry into metamorphosis in the beetle Tribolium castaneum. Proceedings of the National Academy of Sciences. 2007; 104:10488-10493.

189. Minakuchi C, Namiki T, Shinoda T. Krüppel homolog 1, an early juvenile hormone-response gene downstream of Methoprene-tolerant, mediates its anti-metamorphic action in the red flour beetle Tribolium castaneum. Developmental Biology. 2009; 325:341-350. [PubMed: 19013451]

190. Kayukawa T, Minakuchi C, Namiki T, Togawa T, Yoshiyama M, Kamimura M, Mita K, Imanishi S, Kiuchi M, Ishikawa Y, et al. Transcriptional regulation of juvenile hormone-mediated induction of Krüppel homolog 1, a repressor of insect metamorphosis. Proceedings of the National Academy of Sciences. 2012; 109:11729-11734.

191. Emlen DJ, Nijhout HF. The development and evolution of exaggerated morphologies in insects. Annual Review of Entomology. 2000; 5:661-708.

192. Oldham S, Bohni R, Stocker H, Brogiolo W, Hafen E. Genetic control of size in Drosophila. Philosophical Transactions of the Royal Society of London Series B-Biological Sciences. 2000; 355:945-952.

193. Kawano K. Horn and wing allometry and male dimorphism in giant rhinoceros beetles (Coleoptera: Scarabaeidae) of tropical Asia and America. Annals of the Entomological Society of America. 1995; 88:92-99.

194. Nijhout HF, Wheeler DE. Growth models of complex allometries in holometabolous insects. American Naturalist. 1996; 148:40-56.

195. Wheeler DE. The developmental basis of worker caste polymorphism in ants. The American Naturalist. 1991; 138:1218-1238.

196. Wilson EO. The origin and evolution of polymorphism in ants. The Quarterly Review of Biology. 1953; 28:136-156. [PubMed: 13074471]

197. Rintelen F, Stocker H, Thomas G, Hafen E. PDK1 regulates growth through Akt and S6K in Drosophila. Proceedings of the National Academy of Sciences. 2001; 98:15020-15025.

198. Tang HY, Smith-Caldas MSB, Driscoll MV, Salhadar S, Shingleton AW. FOXO regulates organspecific phenotypic plasticity in Drosophila. PLoS Genetics. 2011; 7:e1002373. [PubMed: 22102829]

199. Montagne J, Stewart MJ, Stocker H, Hafen E, Kozma SC, Thomas G. Drosophila S6 kinase: A regulator of cell size. Science. 1999; 285:2126-2129. [PubMed: 10497130] 
200. Brennan CA, Ashburner M, Moses K. Ecdysone pathway is required for furrow progression in the developing Drosophila eye. Development. 1998; 125:2653-2664. [PubMed: 9636080]

201. Brennan CA, Li TR, Bender M, Hsiung F, Moses K. Broad-complex, but not ecdysone receptor, is required for progression of the morphogenetic furrow in the Drosophila eye. Development. 2001; 128:1-11. [PubMed: 11092806]

202. Mou X, Duncan DM, Baehrecke EH, Duncan I. Control of target gene specificity during metamorphosis by the steroid response gene E93. Proceedings of the National Academy of Sciences. 2012; 109:2949-2954.

203. Schubiger M, Carré C, Antoniewski C, Truman JW. Ligand-dependent de-repression via EcR/USP acts as a gate to coordinate the differentiation of sensory neurons in the Drosophila wing. Development. 2005; 132:5239-5248. [PubMed: 16267093]

204. Martin P, Shearn A. Development of Drosophila imaginal discs in vitro: effects of ecdysone concentration and insulin. J Exp Zool. 1980; 211:291-301.

205. Tobler A, Nijhout HF. A switch in the control of growth of the wing imaginal disks of Manduca sexta. PLoS ONE. 2010; 5:e10723. [PubMed: 20502707]

206. Berreur P, Bougues R. Effects of ecdysone on the in vivo growth of wing disks of Calliphora erythrocephala. Journal of Insect Physiology. 1975; 21:915-919.

207. Shingleton AW, Mirth CK, Bates PW. Developmental model of static allometry in holometabolous insects. Proceedings of the Royal Society: Biological Sciences Series B. 2008; 275:1875-1885.

208. MacWhinnie SGB, Allee JP, Nelson CA, Riddiford LM, Truman JW, Champlin DT. The role of nutrition in creation of the eye imaginal disc and initiation of metamorphosis in Manduca sexta. Developmental Biology. 2005; 285:285-297. [PubMed: 16099447]

209. Koyama T, Syropyatova M, Riddiford L. Insulin/IGF signaling regulates the change in commitment in imaginal discs and primordia by overriding the effect of juvenile hormone. Developmental Biology. 2008

210. Rusten TE, Lindmo K, Juhasz G, Sass M, Seglen PO, Brech A, Stenmark H. Programmed autophagy in the Drosophila fat body is induced by ecdysone through regulation of the PI3K pathway. Developmental Cell. 2004; 7:179-192. [PubMed: 15296715]

211. Shingleton AW, Das J, Vinicius L, Stern DL. The temporal requirements for insulin signaling during development in Drosophila. PLoS Biology. 2005; 3:e289. [PubMed: 16086608]

212. Slaidina M, Delanoue R, Gronke S, Partridge L, Leopold P. A Drosophila insulin-like peptide promotes growth during nonfeeding states. Developmental Cell. 2009; 17:874-884. [PubMed: 20059956]

213. Erezyilmaz DF, Riddiford LM, Truman JW. The pupal specifier broad directs progressive morphogenesis in a direct-developing insect. Proceedings of the National Academy of Sciences. 2006; 103:6925-6930.

214. Hutchinson J, McNamara J, Houston A, Vollrath F. Dyar's Rule and the Investment Principle: optimal moulting strategies if feeding rate is size-dependent and growth is discontinuous. Philosophical Transactions of the Royal Society London B Biological Sciences. 1997; 352:113138.

215. Klingenberg CP, Zimmermann M. Dyar's rule and multivariate allometric growth in nine species of waterstriders (Heteroptera: Gerridae). Journal of Zoology. 1992; 227:453-464.

216. Erezyilmaz D, Riddiford L, Truman J. Juvenile hormone acts at embryonic molts and induces the nymphal cuticle in the direct-developing cricket. Development Genes and Evolution. 2004; 214:313-323. [PubMed: 15170568]

217. Konopova B, Smykal V, Jindra M. Common and distinct roles of juvenile hormone signaling genes in metamorphosis of holometabolous and hemimetabolous insects. PLoS ONE. 2011; 6:e28728. [PubMed: 22174880]

218. Huang J-H, Lozano J, Belles X. Broad-complex functions in postembryonic development of the cockroach Blattella germanica shed new light on the evolution of insect metamorphosis. Biochimica Biophysica Acta. 2013; 1830:2178-2187.

219. Bowers WS. How anti-juvenile hormones work. American Zoologist. 1981; 21:737-742. 
220. Bowers WS, Martinez-Pardo R. Antiallatotropins: inhibition of corpus allatum development. Science. 1977; 197:1369-1371. [PubMed: 17747008]

221. Mahfooz N, Turchyn N, Mihajlovic M, Hrycaj S, Popadić A. Ubx regulates differential enlargement and diversification of insect hind legs. PLoS ONE. 2007; 2:e866. [PubMed: 17848997]

222. Mahfooz NS, Li H, Popadić A. Differential expression patterns of the hox gene are associated with differential growth of insect hind legs. Proceedings of the National Academy of Sciences. 2004; 101:4877-4882.

223. Gabriel JM. The development of the locust jumping mechanism: I. Allometric growth and its effect on jumping performance. Journal of Experimental Biology. 1985; 118:313-326.

224. Moczek AP, Nagy LM. Diverse developmental mechanisms contribute to different levels of diversity in horned beetles. Evolution \& Development. 2005; 7:175-185. [PubMed: 15876190]

225. Moczek AP, Rose DJ. Differential recruitment of limb patterning genes during development and diversification of beetle horns. Proceedings of the National Academy of Sciences. 2009; 106:8992-8997.

226. Tanaka K, Truman J. Development of the adult leg epidermis in Manduca sexta: contribution of different larval cell populations. Development Genes and Evolution. 2005; 215:78-89. [PubMed: 15647943]

227. Tanaka K, Truman JW. Molecular patterning mechanism underlying metamorphosis of the thoracic leg in Manduca sexta. Developmental Biology. 2007; 305:539-550. [PubMed: 17418115]

228. Emlen DJ, Allen CE. Genotype to phenotype: physiological control of trait size and scaling in insects. Integrative and Comparative Biology. 2003; 43:617-634. [PubMed: 21680471]

229. Emlen DJ, Nijhout HF. Hormonal control of male horn length dimorphism in Onthophagus taurus (Coleoptera: Scarabaeidae): a second critical period of sensitivity to juvenile hormone. Journal of Insect Physiology. 2001; 47:1045-1054. [PubMed: 11472767]

230. Emlen DJ, Warren IA, Johns A, Dworkin I, Lavine LC. A Mechanism of extreme growth and reliable signaling in sexually selected ornaments and weapons. Science. 2012; 337:860-864. [PubMed: 22837386]

231. Moczek AP, Emlen DJ. Male horn dimorphism in the scarab beetle, Onthophagus taurus: do alternative reproductive tactics favour alternative phenotypes? Animal Behaviour. 2000; 59:459466. [PubMed: 10675268]

232. Moczek AP. Allometric plasticity in a polyphenic beetle. Ecological Entomology. 2002; 27:5867.

233. Emlen DJ. Environmental control of horn length dimorphism in the beetle Onthophagus acuminatus (Coleoptera: Scarabaeidae). Proceedings of the Royal Society B: Biological Sciences. 1994; 256:131-136.

234. Emlen DJ. Artificial selection on horn length-body size allometry in the horned beetle Onthophagus acuminatus (Coleoptera: Scarabaeidae). Evolution. 1996:1219-1230.

235. Emlen DJ. Diet alters male horn allometry in the beetle Onthophagus acuminatus (Coleoptera: Scarabaeidae). Proceedings of the Royal Society B: Biological Sciences. 1997; 264:567-574.

236. Shingleton AW, Tang HY. Plastic flies: The regulation and evolution of trait variability in Drosophila. Fly. 2012; 6:147-152. [PubMed: 22705976]

237. Tobler A, Nijhout HF. Developmental constraints on the evolution of wing-body allometry in Manduca sexta. Evolution \& Development. 2010; 12:592-600. [PubMed: 21040425] 


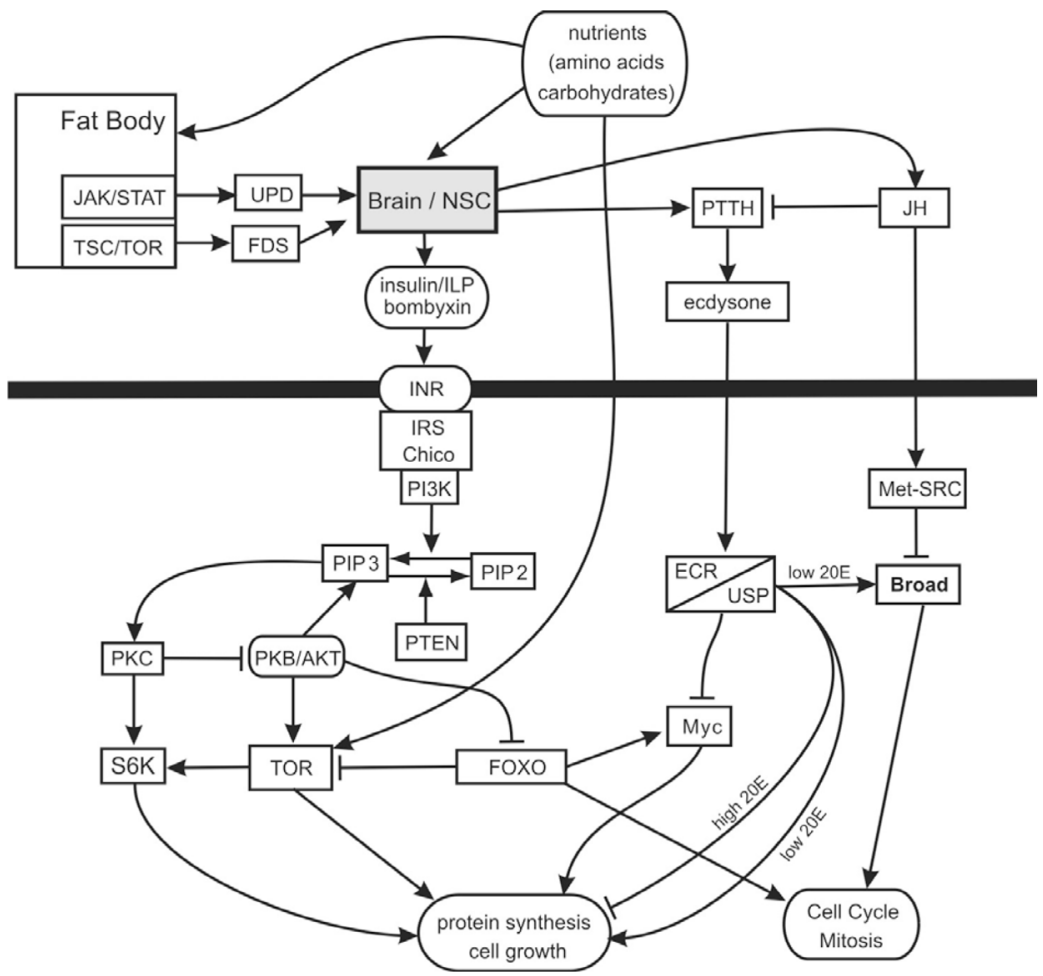

Figure 1. Insulin-nutrition response pathways that regulate growth

This is the general pathway discussed in the text. Nutrients stimulate the insulin, PTTH/ ecdysone and TOR pathways. Although the entire pathway is potentially present in all cells, not all these reactions occur at the same time in development, and different tissues such as fat body and imaginal discs may express different subsets of this complex signaling system. $\mathrm{JH}$ can inhibit or direct ecdysone signaling depending on tissue and developmental stage. 


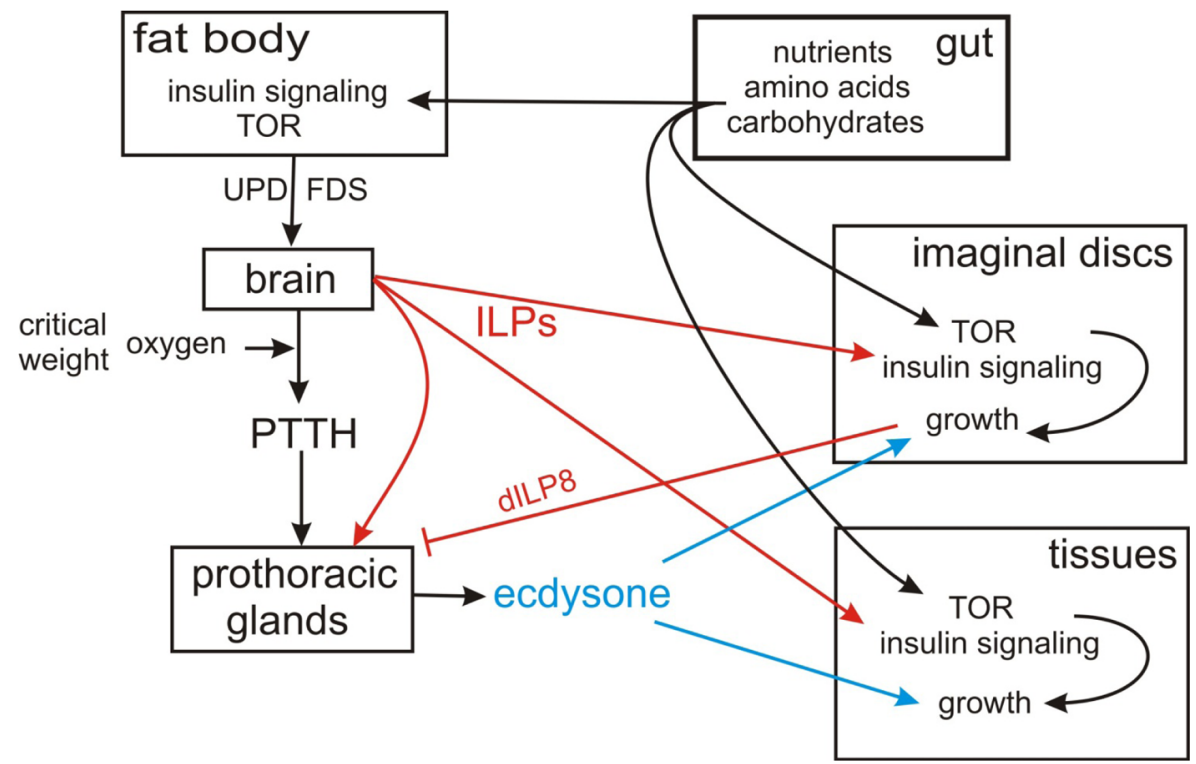

Figure 2. Inter-organ signaling pathways that regulate growth

Growth depends on nutrient input, but is mediated by TOR, insulin (ILP) and ecdysone signaling in each tissue. Details of the intracellular signaling pathways are shown in Figure 1. The PTTH-ecdysone axis appears to be universal, as are the ILP-pathways and the amino acid-TOR axis. Other interactions illustrated have been studied in only one or two species and in relatively few tissues. 


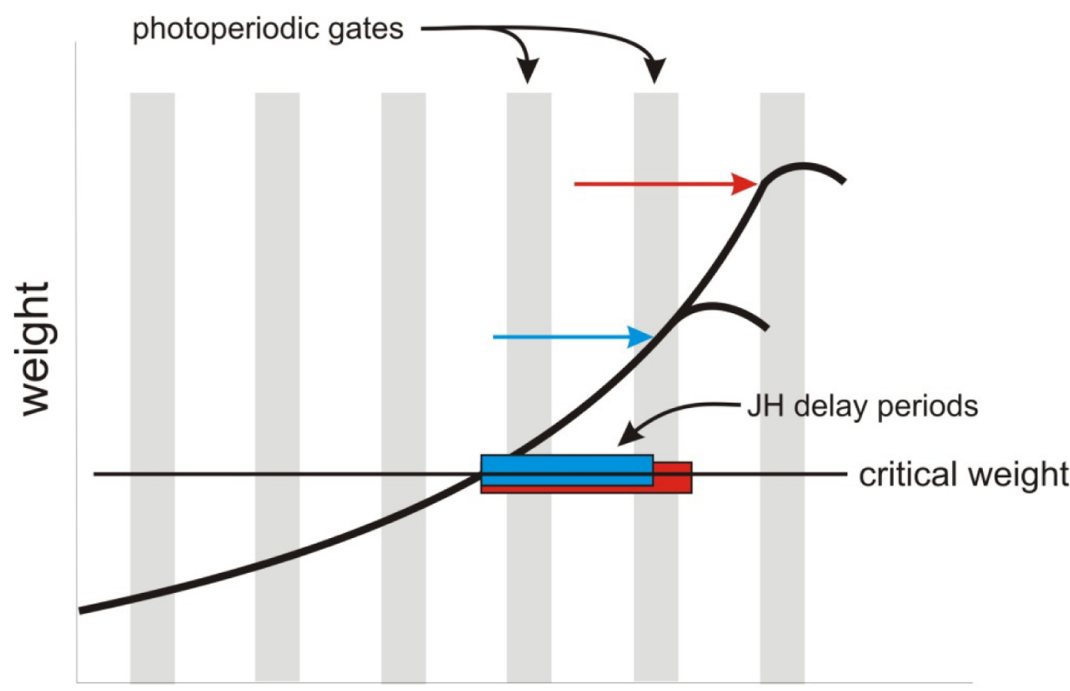

Time

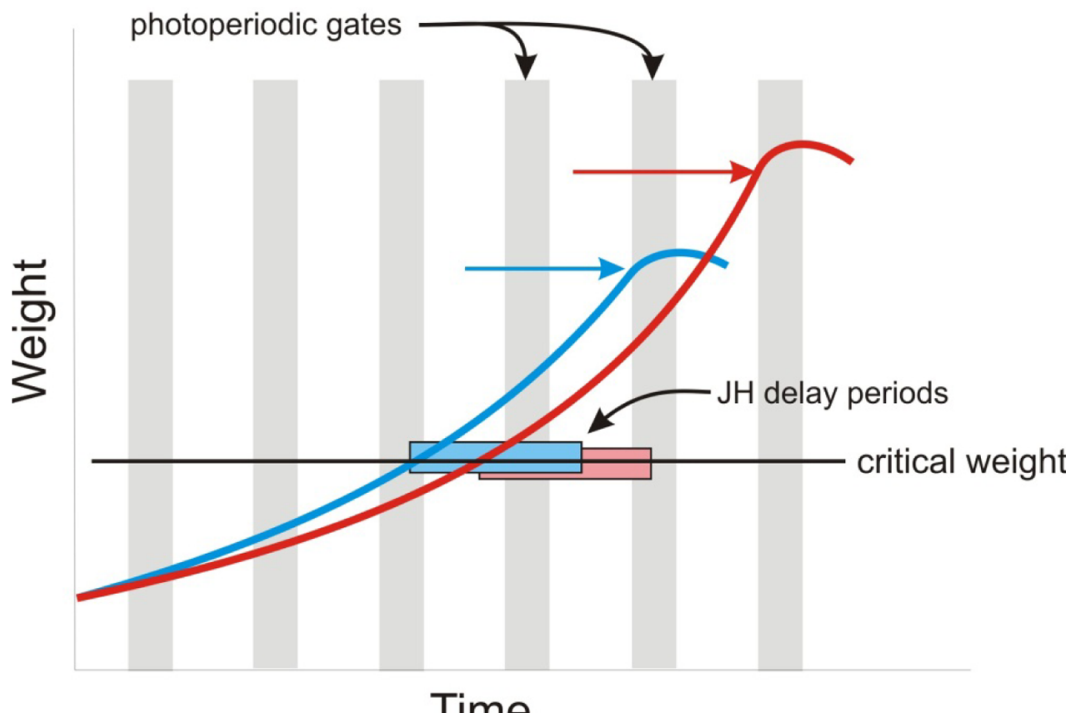

Figure 3. Roles of genes, nutrition and photoperiod in regulating body size in Manduca Body size depends on the signal that causes growth to stop. In insects this signal is the secretion of ecdysone, whose secretion is regulated by PTTH. PTTH secretion is inhibited by $\mathrm{JH}$ and gated by the photoperiod. The top panel illustrates a hypothetical scenario in which genetic differences in the rate of JH breakdown affect the duration of the period required for $\mathrm{JH}$ elimination after the larva passes the critical weight (red and blue bars). A slower rate of JH decay results in a larger body size. The bottom panel illustrates the effect of environmental variation on growth rate. Slower growth rate (without a change in the rate of JH decay) can cause larvae to miss a photoperiodic gate and stop growing at the next one, at a larger body size. 


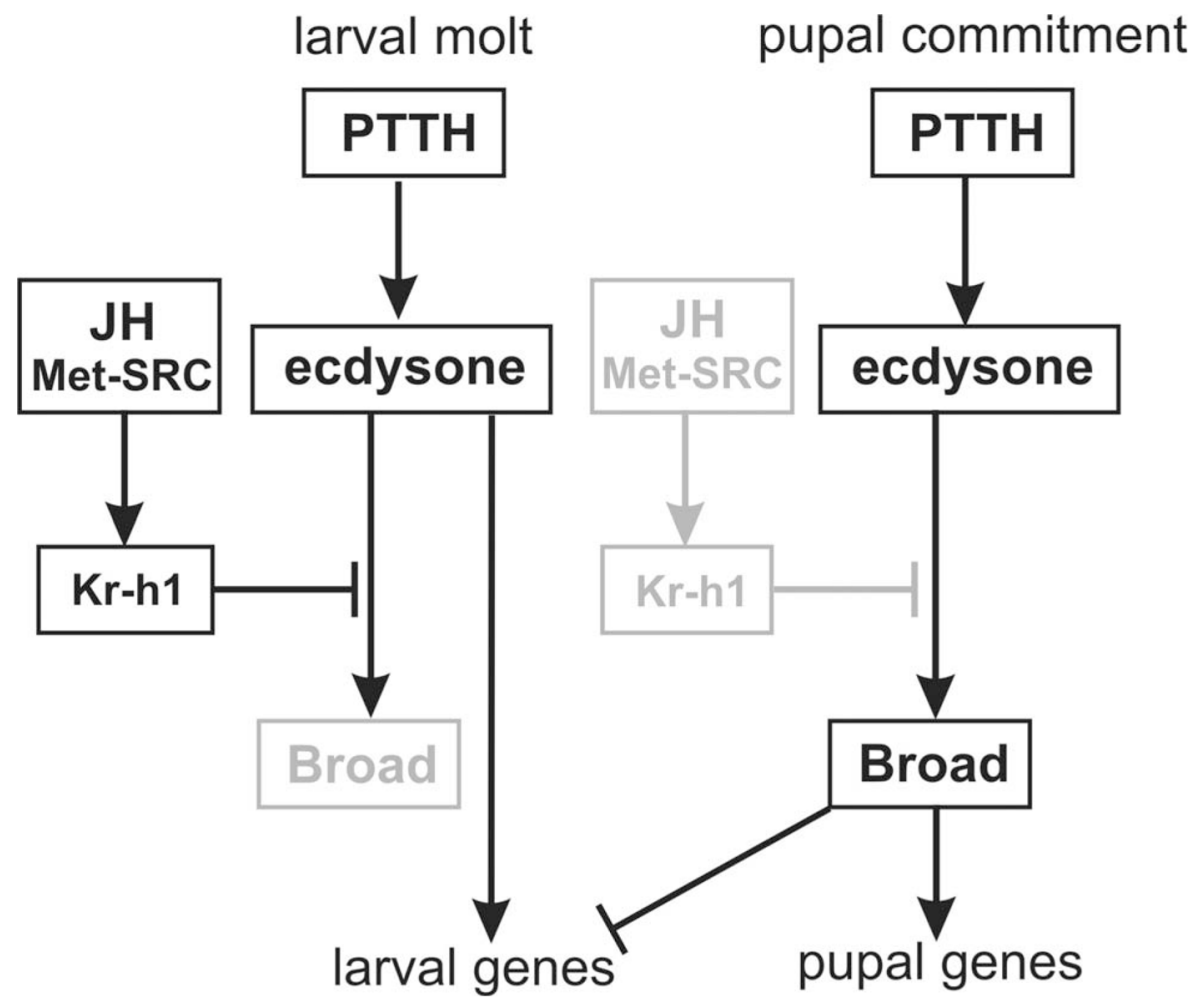

Figure 4. Broad mediates the effects of ecdysone and JH on pupal gene expression during metamorphosis

During larval molts JH inhibits Broad so larval genes remain active and pupal gene expression is repressed. In the last larval stage of Manduca (but not in earlier instars, nor in Drosophila) JH also inhibits PTTH secretion. When JH disappears in the last larval instar, ecdysone-stimulated activation of Broad induces pupal commitment and represses expression of larval genes. 